\title{
Parameter Estimation of Modified Double-Diode and Triple-Diode Photovoltaic Models Based on Wild Horse Optimizer
}

\author{
Abdelhady Ramadan ${ }^{1}$, Salah Kamel ${ }^{1, *(\mathbb{D})}$, Ibrahim B. M. Taha ${ }^{2}$ and Marcos Tostado-Véliz ${ }^{3, *(D)}$ \\ 1 Department of Electrical Engineering, Faculty of Engineering, Aswan University, Aswan 81542, Egypt; \\ eng.abdalhady@gmail.com \\ 2 Department of Electrical Engineering, College of Engineering, Taif University, \\ P.O. Box 11099, Taif 21944, Saudi Arabia; i.taha@tu.edu.sa \\ 3 Electrical Engineering Department, University of Jaen, 23071 Jaen, Spain \\ * Correspondence: skamel@aswu.edu.eg (S.K.); mtostado@ujaen.es (M.T.-V.)
}

check for updates

Citation: Ramadan, A.; Kamel, S.; Taha, I.B.M.; Tostado-Véliz, M. Parameter Estimation of Modified Double-Diode and Triple-Diode Photovoltaic Models Based on Wild Horse Optimizer. Electronics 2021, 10, 2308. https://doi.org/10.3390/ electronics10182308

Academic Editors: Juan M. Corchado, Javid Taheri and Stefanos Kollias

Received: 30 August 2021

Accepted: 16 September 2021

Published: 19 September 2021

Publisher's Note: MDPI stays neutral with regard to jurisdictional claims in published maps and institutional affiliations.

Copyright: (c) 2021 by the authors. Licensee MDPI, Basel, Switzerland. This article is an open access article distributed under the terms and conditions of the Creative Commons Attribution (CC BY) license (https:// creativecommons.org/licenses/by/ $4.0 /)$.

\begin{abstract}
The increase in industrial and commercial applications of photovoltaic systems (PV) has a significant impact on the increase in interest in studying the improvement of the efficiency of these systems. Estimating the efficiency of PV is considered one of the most important problems facing those in charge of manufacturing these systems, which makes it interesting to many researchers. The difficulty in estimating the efficiency of PV is due to the high non-linear current-voltage characteristics and power-voltage characteristics. In addition, the absence of ample efficiency information in the manufacturers' datasheets has led to the development of an effective electrical mathematical equivalent model necessary to simulate the PV module. In this paper, an application for an optimization algorithm named Wild Horse Optimizer (WHO) is proposed to extract the parameters of a double-diode PV model (DDM), modified double-diode PV model (MDDM), triple-diode PV model (TDM), and modified triple-diode PV model (MTDM). This study focuses on two main objectives. The first concerns comparing the original models (DDM and TDM) and their modification (MDDM and MTDM). The second concerns the algorithm behavior with the optimization problem and comparing this behavior with other recent algorithms. The evaluation process uses different methods, such as Root Mean Square Error (RMSE) for accuracy and statistical analysis for robustness. Based on the results obtained by the $\mathrm{WHO}$, the estimated parameters using the $\mathrm{WHO}$ are more accurate than those obtained by the other studied optimization algorithms; furthermore, the MDDM and MTDM modifications enhanced the original DDM and TDM efficiencies.
\end{abstract}

Keywords: photovoltaic; modified triple-diode model; modified double-diode model; optimization; wild horse optimizer

\section{Introduction}

The excessive use of non-renewable energy sources such as fossil fuels is of increasing global concern. The incomplete combustion of fossil fuels in power generation and its associated emissions are the main concerns. The emissions resulting from this incomplete combustion have led to negative effects on the environment, humans, and many living organisms [1]. All these concerns impacted the scientific trend of paying attention to renewable energy sources, discovering more, and developing them to achieve the best efficiency [2]. Solar energy is one of the most important renewable energy sources due to its cleanliness and environmental friendliness. Although the cost of operating and maintaining solar power plants is relatively low, it still has various limitations on efficient power generation. Improving the efficiency of solar power plants is a topic of great interest in the scientific community. In literature, little research has been proposed to improve the power output efficiency of solar power plants [3,4]. The main component of solar 
power plants is the photovoltaic (PV) module, which consists of a series of photocells. The main problem concerning PV cells is the non-linear voltage current characteristics. These non-linear characteristics influence the prediction of the PV cell behavior on different operating conditions. This issue increases the importance of developing an accurate model to test the cell behavior in different operation conditions, to increase the cell efficiency. Different PV models have been proposed to represent most of the cell characteristics.

Well known PV models are based on the diode, for example, single-diode models (SDM), DDM and TDM. SDM is characterized by satisfactory performance and simplicity because it consists of one diode connected with two resistances, one in series and the other in parallel, forming a sum of five parameters. Therefore, it is the most common model [5-9]. DDM differs from SDM with a second diode, which raises the number of the parameters to seven, so the model complexity increases, however, the accuracy increases [10-13]. TDM is considered the most complex model because it contains triple-diodes that represent the behaviors of some types of cells. TDM needs computational power to calculate nine different parameters [14-17]. Some modifications for these models are also proposed in the literature by adding a series resistance with one diode to represent the quasi-neutral region losses. This modification has been applied to the three models, so were named modified SDM (MSDM), modified DDM (MDDM), and modified TDM (MTDM) [18-20].

Different methods in the literature have been proposed to estimate an accurate model using analytical methods such as the Newton-Raphson method [21] and non-linear least square [22]. The disadvantage of analytical methods is that they are difficult and less accurate, especially with complicated models [23]. The most popular techniques in the literature are population-based algorithms. Population-based algorithms are characterized by their ability to overcome local optima problems, in addition to their capabilities to deal with multi-objective problems. They are also characterized by their ability to deal directly with linear and non-linear inequality and equality constraints and are applicable to various optimization problems with few limitations of the problem type. For example, continuity or differentiation in the problem is not required [24]. Different population types of algorithms are proposed in the literature for PV parameters optimization [25]. A survey on the critical analysis of the applied metaheuristic algorithms for PV parameters optimization of different PV models since 2017 was proposed [25]. This survey included Teaching-LearningBased Optimization (TLBO), Genetic Algorithm (GA), Particle Swarm Optimization (PSO), Harmony Search (HS), Simulated Annealing (SA), and Flower Pollination Algorithm (FPA). Recent different algorithms in literature include a proposed Turbulent Flow of Water Optimizer (TFWO) for estimating the optimal values for different PV models [26], a proposal to optimize the parameters of DDM and SDM by an improvement of the equilibrium optimizer using Linear Reduction Diversity technique (LRD) and local Minima Elimination Method (MEM) [27], and a parameters estimation for TDM using Chaos Game Optimization algorithm (CGO) and Improved Grey Wolf Optimizer (I-GWO) by [28] and [29], respectively. The algorithms' behavior in the two references was tested through different evaluation methods. Wild Horse Optimizer (WHO) [30], is a recent populationbased algorithm inspired by horses' social organization behavior. In this study, the WHO has been applied to estimate the parameters of MDDM and MTDM and compare the obtained results with original DDM and TDM to shed light on the accuracy of the modified models versus the original ones through valuable evaluation methods, and present the advantages of WHO with PV parameters optimization problem, which has been considered a difficult optimization problem. The results obtained from the WHO have been compared with other recent optimization algorithms such as I-GWO, CGO and HBO. In addition, the results obtained from the $\mathrm{WHO}$ have been evaluated and compared with results obtained from other references for recent optimization methods such as Bald Eagle Search (BES) [18], elephant herd optimization (EHO) [19], and Turbulent Flow of Water-Based Optimization (TFWO) [20]. The comparison presents the accuracy and robustness of the WHO over these methods.

The rest of this paper is arranged as follows: 
Section 2 presents the PV mathematical modeling and optimization problem. A discussion about the $\mathrm{WHO}$ is presented in Section 3. The results and analysis are discussed in Section 4. Section 5 presents the conclusion.

\section{PV Mathematical Modeling and Optimization Problem} cussed.

In this section, the equivalent circuits for DDM, MDDM, TDM and MTDM are dis-

\section{1. $D D M$ and $M D D M$}

The DDM consists of two diodes with seven parameters as described in Equations (1) and (2). The main seven parameters are $x=\left[x_{1}, x_{2}, x_{3}, x_{4}, x_{5}, x_{6}, x_{7}\right]$ equivalent to $\left[R_{s}\right.$, $\left.R_{s h}, I_{p h}, I_{s 1}, I_{s 2}, \eta_{1}, \eta_{2}\right]$. The DDM objective function is described in Equation (3). Figure 1 presents DDM detailed equivalent circuit.

$$
\begin{gathered}
I=I_{p h}-I_{D 1}-I_{D 2}-I_{s h} \\
I=I_{p h}-I_{s 1}\left[\exp \left(\frac{q\left(V+R_{s} \times I\right)}{\eta_{1} \times K \times T}\right)-1\right]-I_{s 2}\left[\exp \left(\frac{q\left(V+R_{s} \times I\right)}{\eta_{2} \times K \times T}\right)-1\right]-\frac{\left(V+R_{s} \times I\right)}{R_{s h}} \\
f_{D D}(V, I, X)=I-X_{3}+X_{4}\left[\exp \left(\frac{q\left(V+X_{1} \times I\right)}{X_{6} \times K \times T}\right)-1\right]+X_{5}\left[\exp \left(\frac{q\left(V+X_{1} \times I\right)}{X_{7} \times K \times T}\right)-1\right]+\frac{\left(V+X_{1} \times I\right)}{X_{2}}
\end{gathered}
$$

Figure 1. DDM.

The MDDM is the same as DDM, but differs by adding series resistance with diode 2 to represent the losses in the space charge region as described in Equation (4). The main eight parameters of MDDM are $x=\left[x_{1}, x_{2}, x_{3}, x_{4}, x_{5}, x_{6}, x_{7}\right]$ equivalent to $\left[R_{s}, R_{s h}, I_{p h}, I_{s 1}, I_{s 2}\right.$, $\left.\eta_{1}, \eta_{2}, R_{s m}\right]$. The objective function for MDDM is described in Equation (5). The equivalent circuit of MDDM is shown in Figure 2.

$$
\begin{gathered}
I=I_{p h}-I_{s 1}\left[\exp \left(\frac{q\left(V+R_{s} \times I\right)}{\eta_{1} \times K \times T}\right)-1\right]-I_{s 2}\left[\exp \left(\frac{q\left(V+R_{s} \times I-R_{s m} \times I_{D 2}\right)}{\eta_{2} \times K \times T}\right)-1\right]-\frac{\left(V+R_{s} \times I\right)}{R_{s h}} \\
f_{D D}(V, I, X)=I-X_{3}+X_{4}\left[\exp \left(\frac{q\left(V+X_{1} \times I\right)}{X_{6} \times K \times T}\right)-1\right]+X_{5}\left[\exp \left(\frac{q\left(V+X_{1} \times I-X_{8} \times I_{D 2}\right)}{X_{7} \times K \times T}\right)-1\right]+\frac{\left(V+X_{1} \times I\right)}{X_{2}}
\end{gathered}
$$

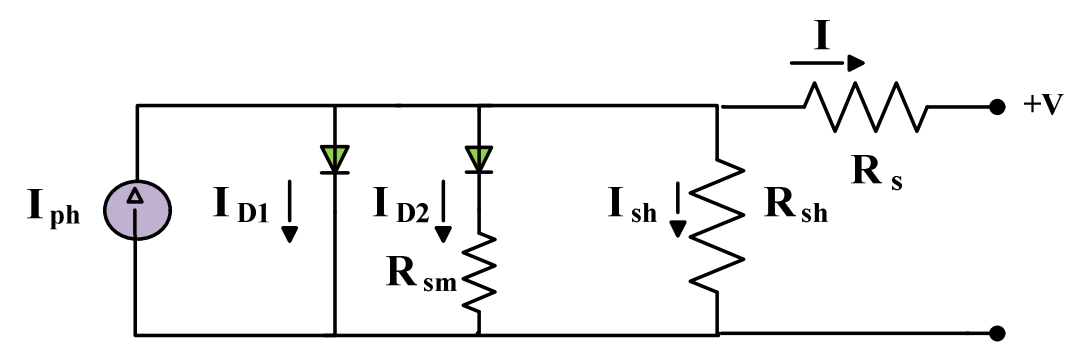

Figure 2. MDDM. 


\subsection{TDM and MTDM}

The TDM consists of triple-diodes with nine parameters as described in Equations (6) and (7).

$$
\begin{gathered}
I=I_{p h}-I_{s 1}-I_{s 2}-I_{s 3}-I_{s h} \\
I=I_{p h}-I_{s 1}\left[\exp \left(\frac{q\left(V+R_{s} \times I\right)}{\eta_{1} \times K \times T}\right)-1\right]-I_{s 2}\left[\exp \left(\frac{q\left(V+R_{s} \times I\right)}{\eta_{2} \times K \times T}\right)-1\right]-I_{s 3}\left[\exp \left(\frac{q\left(V+R_{s} \times I\right)}{\eta_{3} \times K \times T}\right)-1\right]-\frac{\left(V+R_{s} \times I\right)}{R_{s h}}
\end{gathered}
$$

Considering the nine parameters listed in $\mathrm{x}$ vector as follows: $x=\left[x_{1}, x_{2}, x_{3}, x_{4}, x_{5}, x_{6}\right.$, $\left.x_{7}, x_{8}, x_{9}\right]$ is equivalent to $\left[R_{s}, R_{s h}, I_{p h}, I_{s 1}, I_{s 2}, I_{s 3}, \eta_{1}, \eta_{2}, \eta_{3}\right]$ where:

- $\quad\left[I_{p h}\right]$ Current source representing the photo-generated current;

- $\quad\left[I_{s 1}\right]$ Current of the first diode representing the cell diffusion current;

- $\quad\left[I_{s 2}\right]$ Current of the second diode representing the cell recombination current;

- $\quad\left[I_{s 3}\right]$ Current of the third diode representing the cell grain boundaries and large leakage current;

- $\left[R_{s}\right]$ Series resistance representing the effect of the semiconductor material resistance at neutral regions;

- $\quad\left[R_{s h}\right]$ Shunt resistance representing the effect of P-N junction leakage current resistance.

The equivalent TDM circuit is presented in Figure 3. The objective function for TDM is described in Equation (8).

$f_{T D}(V, I, X)=I-X_{3}+X_{4}\left[\exp \left(\frac{q\left(V+X_{1} \times I\right)}{X_{7} \times K \times T}\right)-1\right]+X_{5}\left[\exp \left(\frac{q\left(V+X_{1} \times I\right)}{X_{8} \times K \times T}\right)-1\right]+X_{6}\left[\exp \left(\frac{q\left(V+X_{1} \times I\right)}{X_{9} \times K \times T}\right)-1\right]+\frac{\left(V+X_{1} \times I\right)}{X_{2}}$

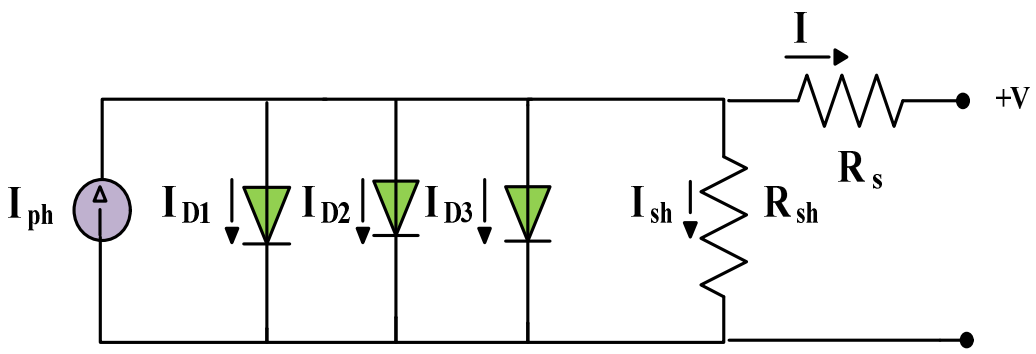

Figure 3. TDM.

The MTDM has a series resistance with diode 2 to represent the losses in the space charge region as described in Equation (9). The main ten parameters of MTDM are $x=$ $\left[x_{1}, x_{2}, x_{3}, x_{4}, x_{5}, x_{6}, x_{7}, x_{8}, x_{9}, x_{10}\right]$ equivalent to $\left[R_{s}, R_{s h}, I_{p h}, I_{s 1}, I_{s 2}, I_{s 3}, \eta_{1}, \eta_{2}, \eta_{3}, R_{s m}\right]$. The objective function for MTDM is described in Equation (10). The equivalent circuit of MTDM is presented in Figure 4.

$$
\begin{array}{r}
I=I_{p h}-I_{s 1}\left[\exp \left(\frac{q\left(V+R_{S} \times I\right)}{\eta_{1} \times K \times T}\right)-1\right]-I_{s 2}\left[\exp \left(\frac{q\left(V+R_{s} \times I\right)}{\eta_{2} \times K \times T}\right)-1\right]-I_{s 3}\left[\exp \left(\frac{q\left(V+R_{s} \times I-R_{s m} \times I_{D 3}\right)}{\eta_{3} \times K \times T}\right)-1\right]-\frac{\left(V+R_{s} \times I\right)}{R_{s h}} \\
f_{T D}(V, I, X)=I-X_{3}+X_{4}\left[\exp \left(\frac{q\left(V+X_{1} \times I\right)}{X_{7} \times K \times T}\right)-1\right]+X_{5}\left[\exp \left(\frac{q\left(V+X_{1} \times I\right)}{X_{8} \times K \times T}\right)-1\right]+X_{6}\left[\exp \left(\frac{q\left(V+X_{1} \times I-X_{10} \times I_{D 3}\right)}{X_{9} \times K \times T}\right)-1\right]+\frac{\left(V+X_{1} \times I\right)}{X_{2}}
\end{array}
$$

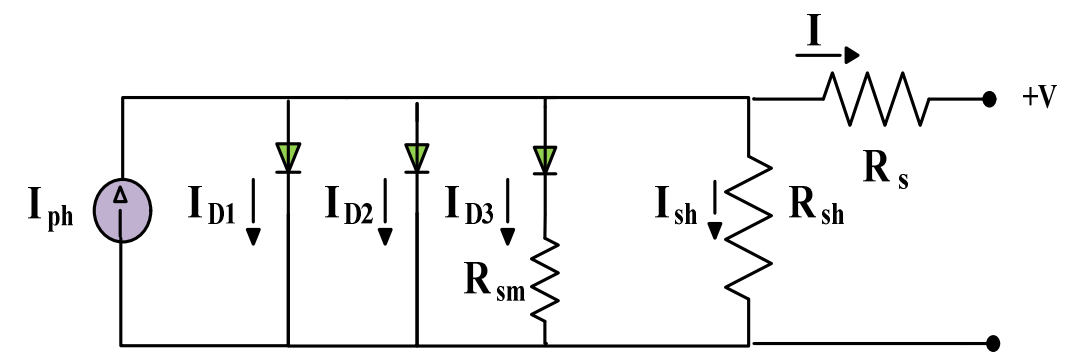

Figure 4. MTDM. 


\section{Wild Horse Optimizer (WHO)}

WHO is an optimization algorithm inspired by the natural life behavior of creatures, such as methods that animals use for obtaining food. The WHO is inspired by the social organizational behavior of horses. This social organization includes bonding and grazing, mating behavior, leadership hierarchy, and dominance. The WHO is based on the social behavior of a specific type of horses called non-terrestrial horses. This behavior is briefly described in the next paragraph.

Horses live in groups considered as families, Figure 5. A family group contains different ages, such as a stallion, mares and offspring. Other groups, called single groups, contain adult stallions. In family groups, stallion and mares remain close to each other to enable communication, and foals graze nearby until they become older. When foals grow up, they leave their families and join single groups to build new families. Male and female foals from one family group join two different single groups. This behavior prevents the father from mating with daughters, or brothers with sisters.

Group 1
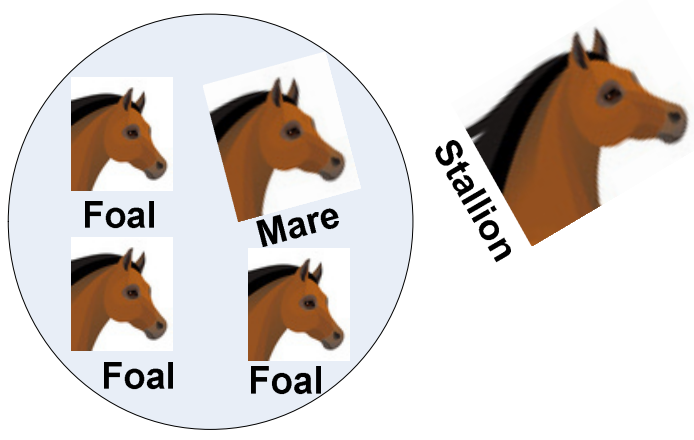

Group $n$
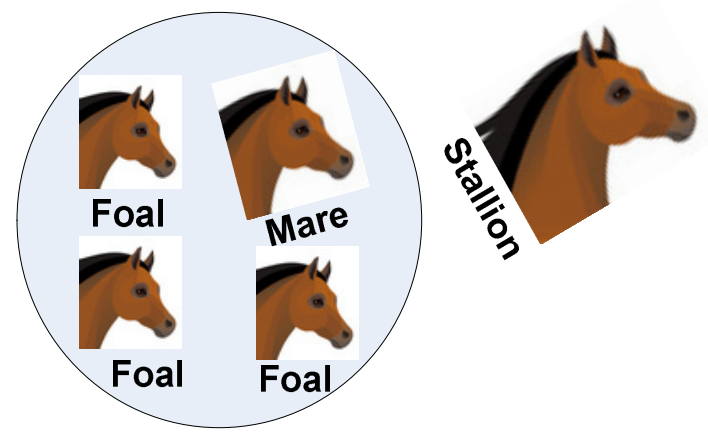

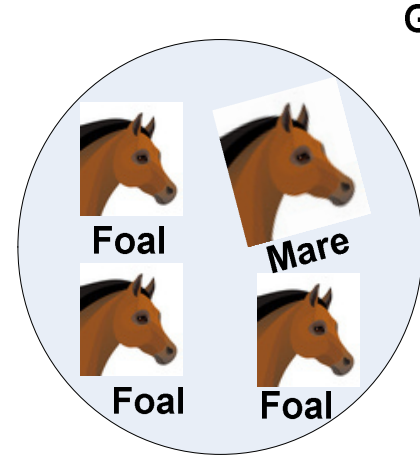

Group 2

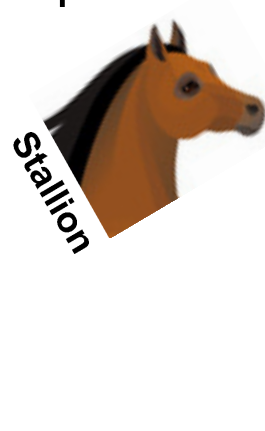

Group 3
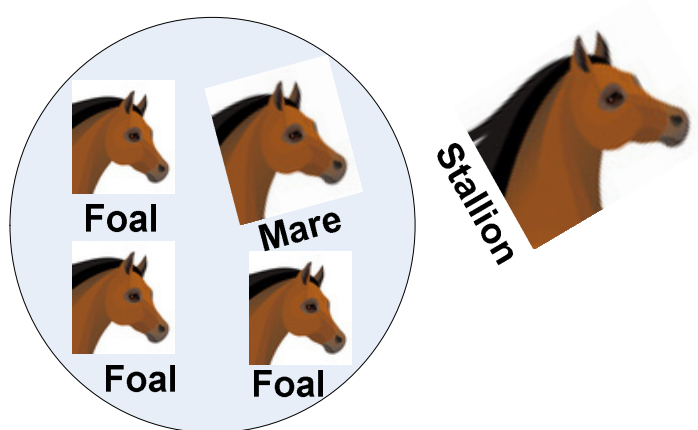

Figure 5. Grouping process of stallions and foals.

The main steps of the WHO are described as follows:

- Starting the problem initialization and collecting groups of horses with their leaders;

- Mating and grazing of horses;

- $\quad$ Leadership of the group (stallion);

- Selecting the leaders and applying to exchange;

- $\quad$ Obtaining the best solutions.

\subsection{Initialization for the Problem}

In this phase, random solutions for the problem are created based on the population number. The best solution is evaluated by selecting the most likely solutions first, then updating them with the algorithm. The number of these groups is considered as 
$G=[N \times P S]$, where $G$ is the group number, $N$ is the population number, and $P S$ is the percentage of stallions to the total population. This grouping process is shown in Figure 6.

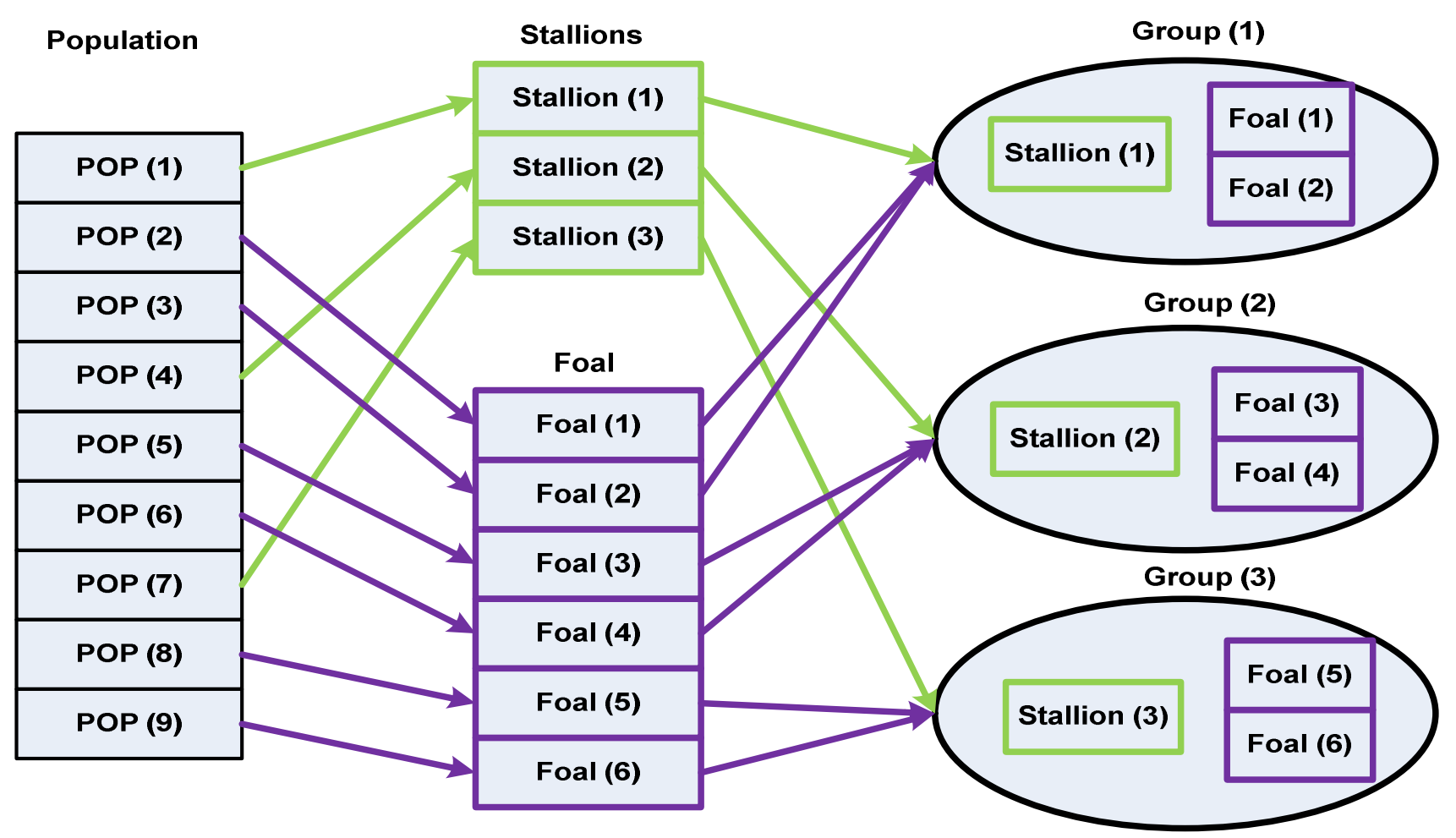

Figure 6. Forming groups from the original population.

\subsection{Grazing Behavior of Horses}

This phase describes foal grazing within its family. The stallion is in the center and surrounded by foals $(X)$. The new positions of group members can be described by Equation (11):

$$
X_{i, G}^{j}=2 Z \cos (2 \pi R Z) \times\left(\text { Stallion }^{j}-X_{i, G}^{j}\right)+\text { Stallion }^{j}
$$

where $Z$ is an adaptive mechanism described by Equation (12), $R$ is a random value within range $[-2,2]$, and $\pi=3.14$. TDR is an adaptive parameter that initializes with 1 and decreases according to Equation (13). Maxiter is the selected maximum number of iterations.

$$
\begin{gathered}
P=\vec{R}_{1}<T D R ; I D X=(P==0) ; Z=R_{2} \Theta I D X+\overrightarrow{R_{3}} \Theta(\sim I D X) \\
T D R=1-\text { iter } \times\left(\frac{1}{\text { Maxiter }}\right)
\end{gathered}
$$

\subsection{Horse Mating Behavior}

This phase describes the behavior of foals when they leave their families and join single groups. The position of foals in this phase is described by Equation (14). This behavior is simulated in Figure 7.

$$
X_{G, k}^{p}=\operatorname{Crossover}\left(X_{G, i}^{q}, X_{G, j}^{Z}\right) i \neq j \neq k, p=q=\text { endCrossover }=\text { mean }
$$




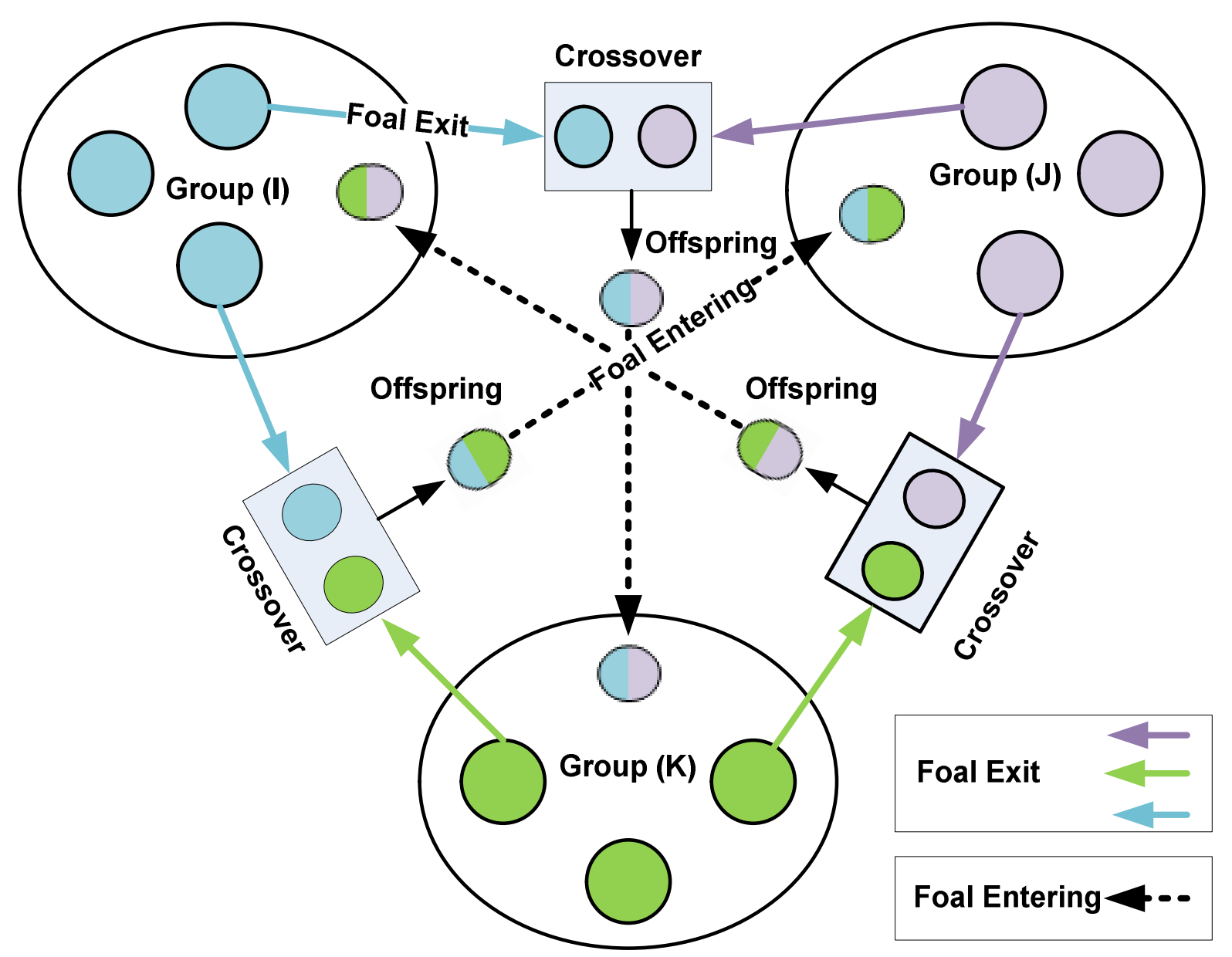

Figure 7. Foals' behavior when leaving their original group and joining a new group.

\subsection{Leadership of Groups}

This phase describes the movement of groups by their leaders to specific spaces, for example, watering holes. The position of groups at this phase is described by Equation (15).

$$
\text { Stallion }_{G i}=\left\{\begin{array}{ll}
2 Z \cos (2 \pi R Z) \times\left(W H-\text { Stallion }_{G i}\right)+W H & \text { if } R_{3}>0.5 \\
2 Z \cos (2 \pi R Z) \times\left(W H-\text { Stallion }_{G i}\right)-W H & \text { if } R_{3} \leq 0.5
\end{array}\right\}
$$

\subsection{Selecting and Exchanging Leaders}

This phase describes the group leader selection. Firstly, the group leader is selected randomly, and then selected by Equation (16):

$$
\text { Stallion }_{G i}=\left\{\begin{array}{cl}
X_{G, i} & \text { if } \cos t\left(X_{G, i}\right)<\cos t\left(\text { Stallion }_{G i}\right) \\
\text { Stallion }_{G i} & \text { if } \cos t\left(X_{G, i}\right)>\cos t\left(\text { Stallion }_{G i}\right)
\end{array}\right\}
$$

The complete algorithm sequence is shown in the WHO flowchart in Figure 8. 


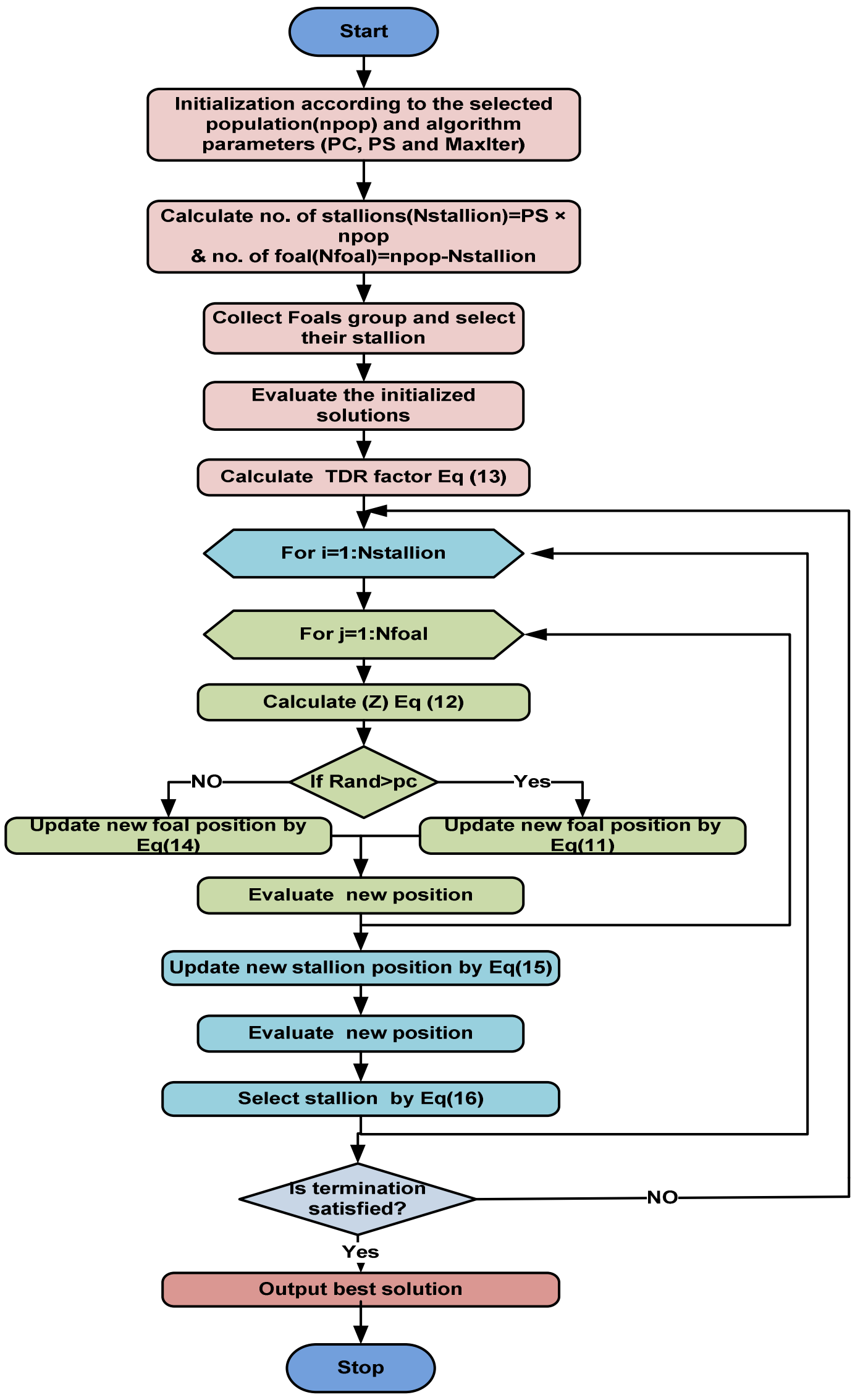

Figure 8. WHO flowchart. 


\section{Results and Discussion}

In this section, the WHO's evaluation will be discussed by checking its performance through parameters estimation of MTDM, TDM, MDDM and DDM, using measured data from real PV systems. For evaluating and analyzing the obtained results, various evaluation methods will be considered. In this section, two different applications are performed. The measured data from the Radiotechnique Compelec (RTC) furnace is firstly considered, and then the Potassium Titanate Whisker (PTW) polycrystalline PV panel's measured data is considered.

\subsection{Results of Radiotechnique Compelec (RTC) Furnace}

The WHO was applied to optimize the parameters of MTDM, TDM, MDDM, and DDM using the measured data from commercial silicon RTC France solar cell, which has a $57 \mathrm{~mm}$ diameter. The data was captured at irradiance $1000 \mathrm{~W} / \mathrm{m}^{2}$ and temperature $33^{\circ} \mathrm{C}$ [10]. The WHO parameters are crossover percentage (PC) of 0.13 and stallions' percentage (PS) of 0.2. The four models' accuracy was tested through the best root mean square error (RMSE) Equation (17) values obtained from the WHO. Table 1 presents the minimum and maximum range of the four models' parameters. The best RMSE and the estimated parameters are presented in Table 2. The WHO convergence curve for all models are presented in Figure 9. The best obtained RMSE value was for MTDM followed by MDDM, and this presents the enhancement of model accuracy by the model modification. The stability of the WHO was tested by running the algorithm for 30 independent runs for MTDM and MDDM, obtaining the statistical analysis, then comparing these results with Bald Eagle Search (BES) [18] and Elephant Herd Optimization (EHO) [19], as shown in Tables 3 and 4, and boxplot Figures 10 and 11. The results of the WHO were more accurate than other algorithms for MTDM and MDDM. The authors of [20] have proposed a detailed study about parameters optimization of original and modified PV models. The authors of [20] have proposed an evaluation parameter called the polynomial equation of five degrees for the sum of squared errors (PE5DSSE) [19,20]. To compare the results of the WHO with [20], PE5DSSE was calculated and presented in Table 2. The best values of PE5DSSE proposed in [20] were $2.51 \times 10^{-5}$ and $2.509 \times 10^{-5}$ for original and modified models, respectively. The best values of PE5DSSE obtained by the WHO, which proved more accurate, were $2.50944 \times 10^{-5}$ and $1.52205 \times 10^{-5}$ for original and modified models, respectively. For detailed analysis of the obtained results by the WHO of all models, the current and power absolute errors (Equation (18)) between the real measured and the estimated current and power values were calculated and presented in Figures 12 and 13 respectively. Figure 14 presents a comparison between the measured current-voltage characteristic curve and that calculated by different models. Figure 15 presents the power-voltage characteristic curve for the real PV measured data and that calculated by different models. The current-voltage and power-voltage characteristic curves for the MTDM estimated by the WHO at different temperatures are displayed in Figures 16 and 17, respectively.

$$
\begin{gathered}
R M S E=\sqrt{\frac{1}{N} \sum_{K=1}^{N} f^{2}\left(V_{t m}, I_{t m}, X\right)} \\
\text { Current Absolut error }=\sqrt[2]{\left(I-I_{\text {estimated }}\right)^{2}} \text { Power Absolut error }=\sqrt[2]{\left(P-P_{\text {estimated }}\right)^{2}} \\
S S E=\sum_{K=1}^{N} f^{2}\left(V_{t m}, I_{t m}, X\right) \\
\text { PE5DSSE }=S S E+S S E^{2}+S S E^{3}+S S E^{4}+S S E^{5}
\end{gathered}
$$


Table 1. Parameter lower and upper constraints.

\begin{tabular}{ccccc}
\hline Parameter & \multicolumn{2}{c}{ Solar Cell } & \multicolumn{2}{c}{ PV Module } \\
\hline & Lower Limit & Upper Limit & Lower Limit & Upper Limit \\
\hline $\mathrm{R}_{\mathrm{s}}$ & 0 & 5 & 0 & 5 \\
$\mathrm{R}_{\mathrm{sh}}$ & 0 & 100 & 0 & 1000 \\
$\mathrm{I}_{\mathrm{ph}}$ & 0 & 2 & 0 & 2 \\
$\mathrm{I}_{\mathrm{s} 1}$ & 0 & 1 & 0 & 1 \\
$\mathrm{I}_{\mathrm{s} 2}$ & 0 & 1 & 0 & 1 \\
$\mathrm{I}_{\mathrm{s} 2}$ & 0 & 1 & 0 & 1 \\
$\eta_{\mathrm{l}}$ & 1 & 2 & 1 & 50 \\
$\eta_{\mathrm{s}}$ & 1 & 2 & 1 & 50 \\
$\eta_{\mathrm{n}}$ & 1 & 2 & 1 & 50 \\
$\mathrm{R}_{\mathrm{sm}}$ & 1 & 0.1 & - & - \\
\hline
\end{tabular}

Table 2. Estimated parameters and RMSE of WHO for original and modified models.

\begin{tabular}{ccccc}
\hline & MTDM & TDM & MDDM & DDM \\
\hline $\mathrm{R}_{\mathrm{s}}(\Omega)$ & 0.031719 & 0.036743 & 0.0045190 & 0.036783 \\
\hline $\mathrm{R}_{\mathrm{sh}}(\Omega)$ & 60 & 55.50765 & 60 & 56.07530 \\
\hline $\mathrm{I}_{\mathrm{ph}}(\mathrm{A})$ & 0.760734 & 0.760781 & 0.760347 & 0.760752 \\
\hline $\mathrm{I}_{\mathrm{s} 1}(\mathrm{~A})$ & $1.97 \times 10^{-6}$ & $7.66 \times 10^{-7}$ & $2.05 \times 10^{-7}$ & $8.002 \times 10^{-7}$ \\
\hline $\mathrm{I}_{\mathrm{s} 2}(\mathrm{~A})$ & $4.73 \times 10^{-9}$ & $1.00 \times 10^{-10}$ & $8.71 \times 10^{-7}$ & $2.2046 \times 10^{-7}$ \\
\hline $\mathrm{I}_{\mathrm{s} 3}(\mathrm{~A})$ & $1.00 \times 10^{-10}$ & $2.26 \times 10^{-7}$ & - & - \\
\hline$\eta_{1}$ & 1.783574 & 2 & 1.48504 & 1.999973 \\
\hline$\eta_{2}$ & 1.197584 & 1.446786 & 1.579685 & 1.448974 \\
\hline$\eta_{3}$ & 1 & 1.446794 & - & - \\
\hline $\mathrm{R}_{\mathrm{sm}}$ & 0.090031 & - & 0.04941 & - \\
\hline $\mathrm{RMSE}$ & 0.00076511 & 0.000982417 & 0.000783 & 0.0009832 \\
\hline $\mathrm{PE5DSSE}$ & $1.52205 \times 10^{-5}$ & $2.50944 \times 10^{-5}$ & $1.59406 \times 10^{-5}$ & $2.51344 \times 10^{-5}$ \\
\hline
\end{tabular}

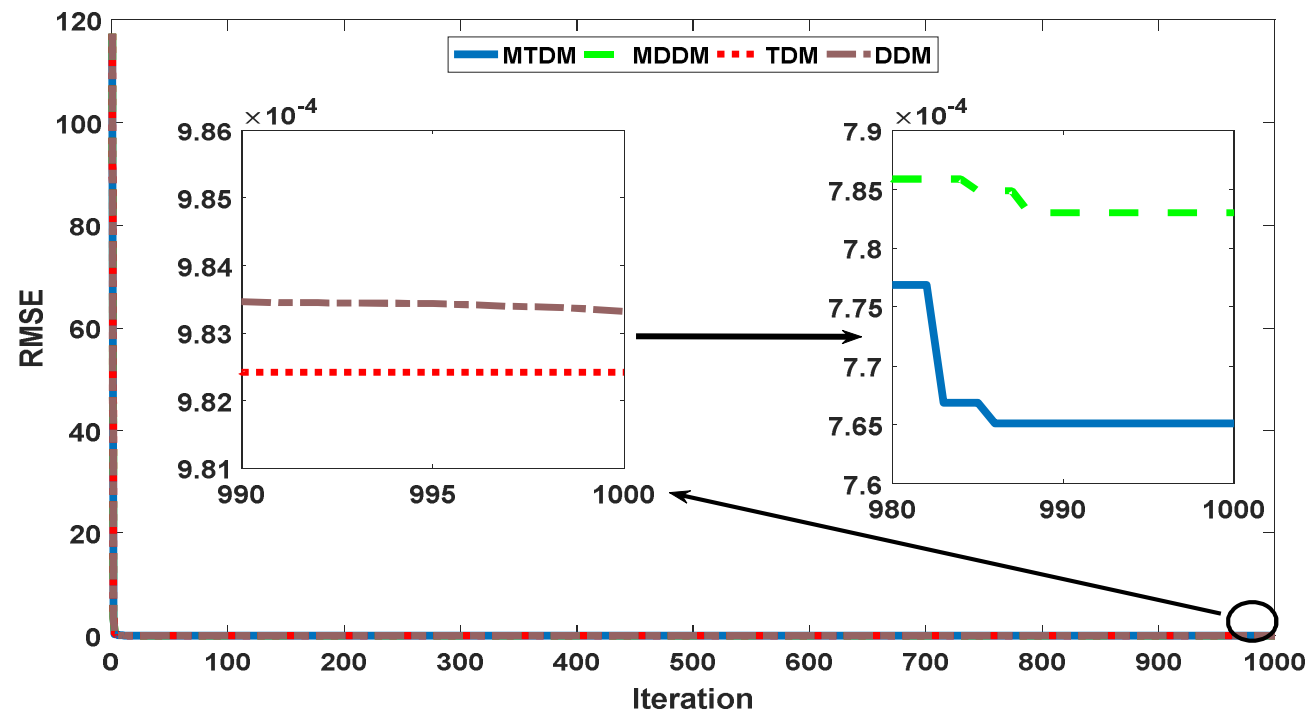

Figure 9. The convergence curve of $\mathrm{WHO}$ for all models. 
Table 3. The statistical results of MTDM for WHO and other algorithms.

\begin{tabular}{ccccc}
\hline MTDM & Minimum & Average & Maximum & STD \\
\hline WHO & 0.00076511 & 0.000842 & 0.000986 & 0.000125 \\
\hline BES [18] & 0.000790747 & 0.000901 & 0.00107848 & 0.00015509 \\
\hline EHO [19] & 0.001233 & 0.0059761 & 0.0131253 & 0.0039343 \\
\hline
\end{tabular}

Table 4. The statistical results of MDDM for WHO and other algorithms.

\begin{tabular}{ccccc}
\hline MDDM & Minimum & Average & Maximum & STD \\
\hline WHO & 0.000783 & 0.000842 & 0.000960371 & 0.000103 \\
\hline BES [18] & 0.000824 & 0.001109 & 0.001603713 & 0.00043 \\
\hline EHO [19] & 0.001557 & 0.0065934 & 0.0132005 & 0.0037673 \\
\hline
\end{tabular}

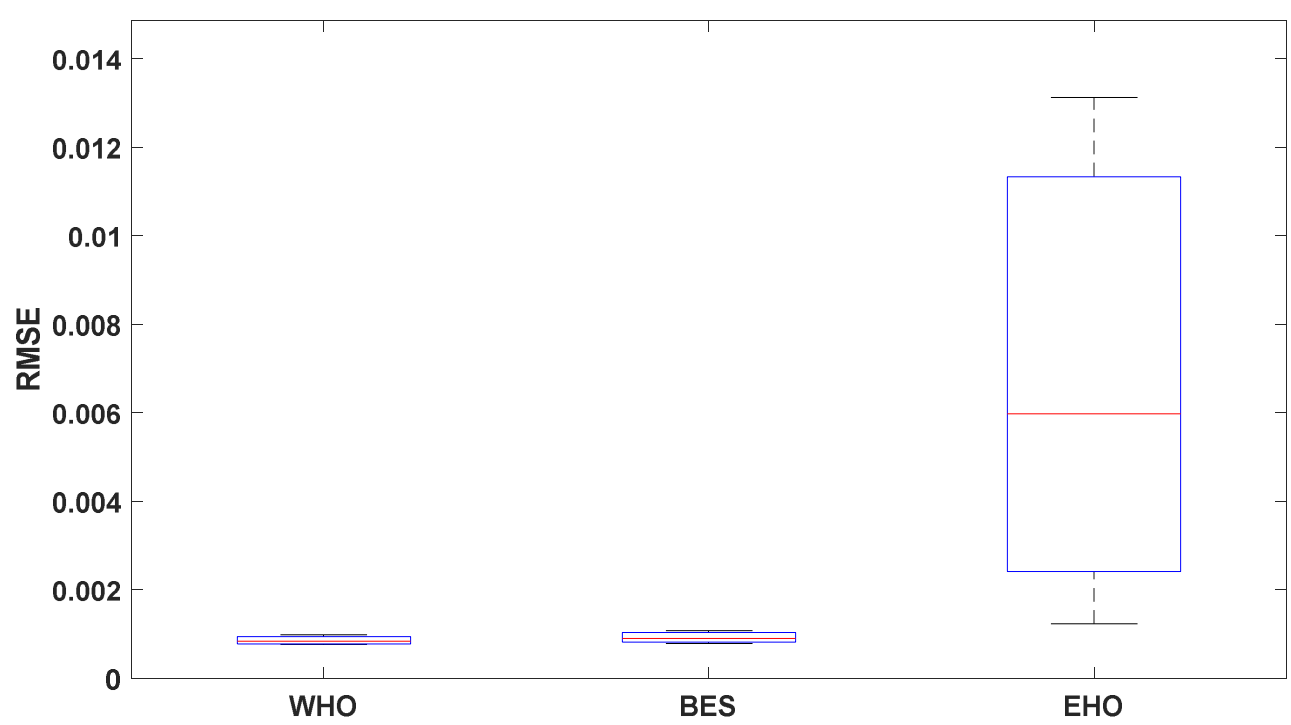

Figure 10. Boxplot figure of all algorithms for 30 independent runs applied to MTDM.

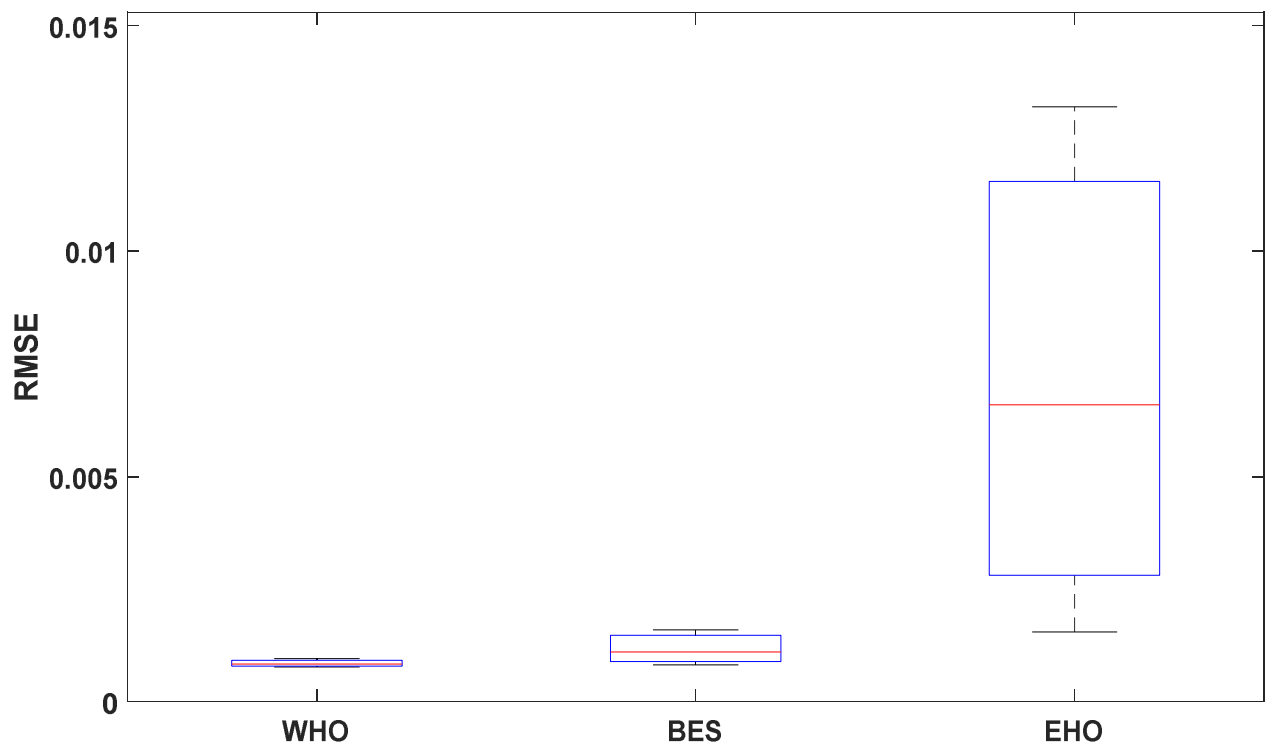

Figure 11. Boxplot of all algorithms for 30 independent runs applied to MDDM. 


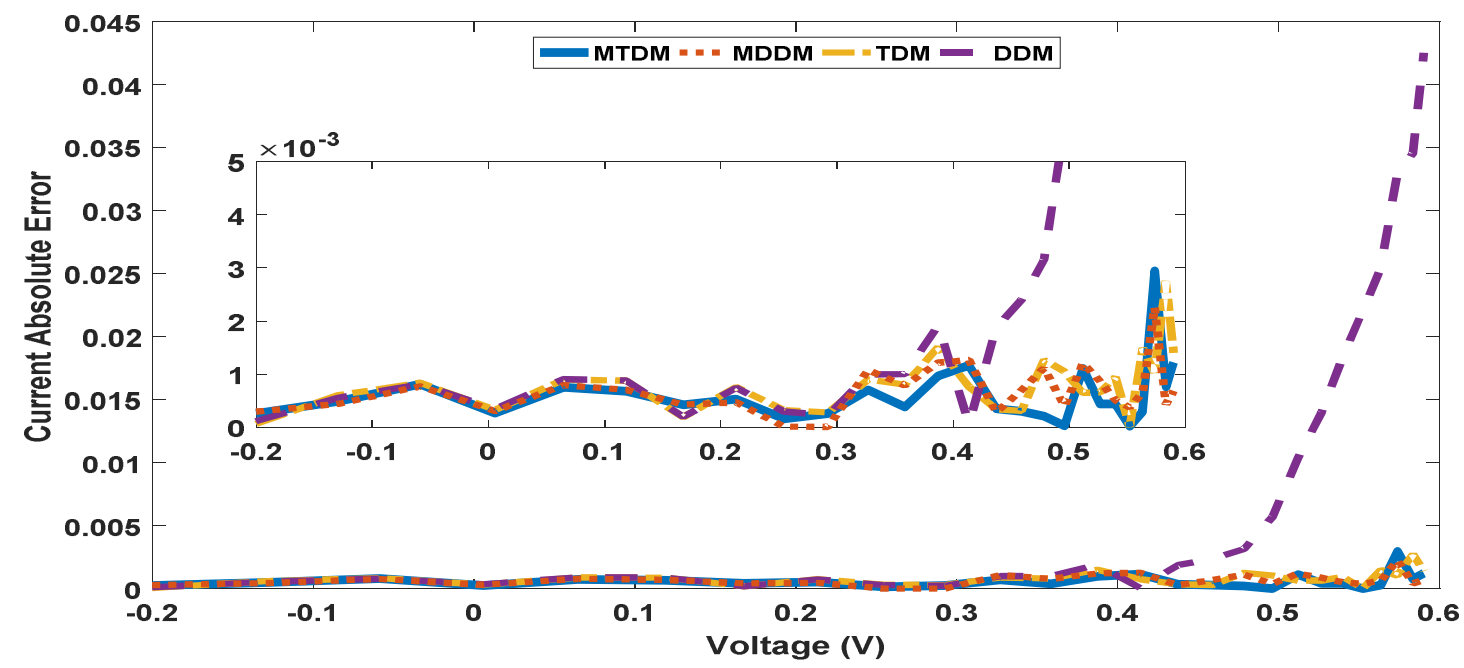

Figure 12. Current absolute error calculated for all models.

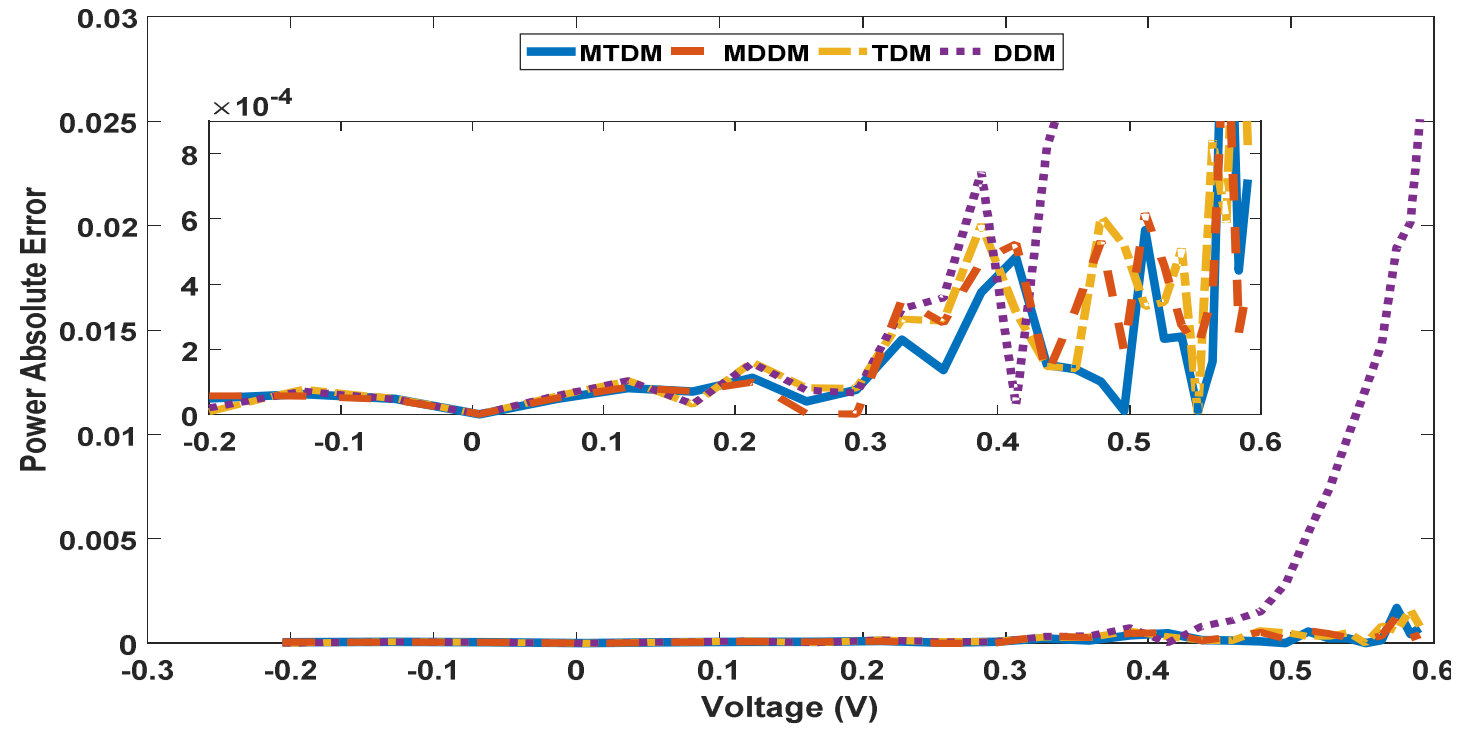

Figure 13. Power absolute error calculated for all models.

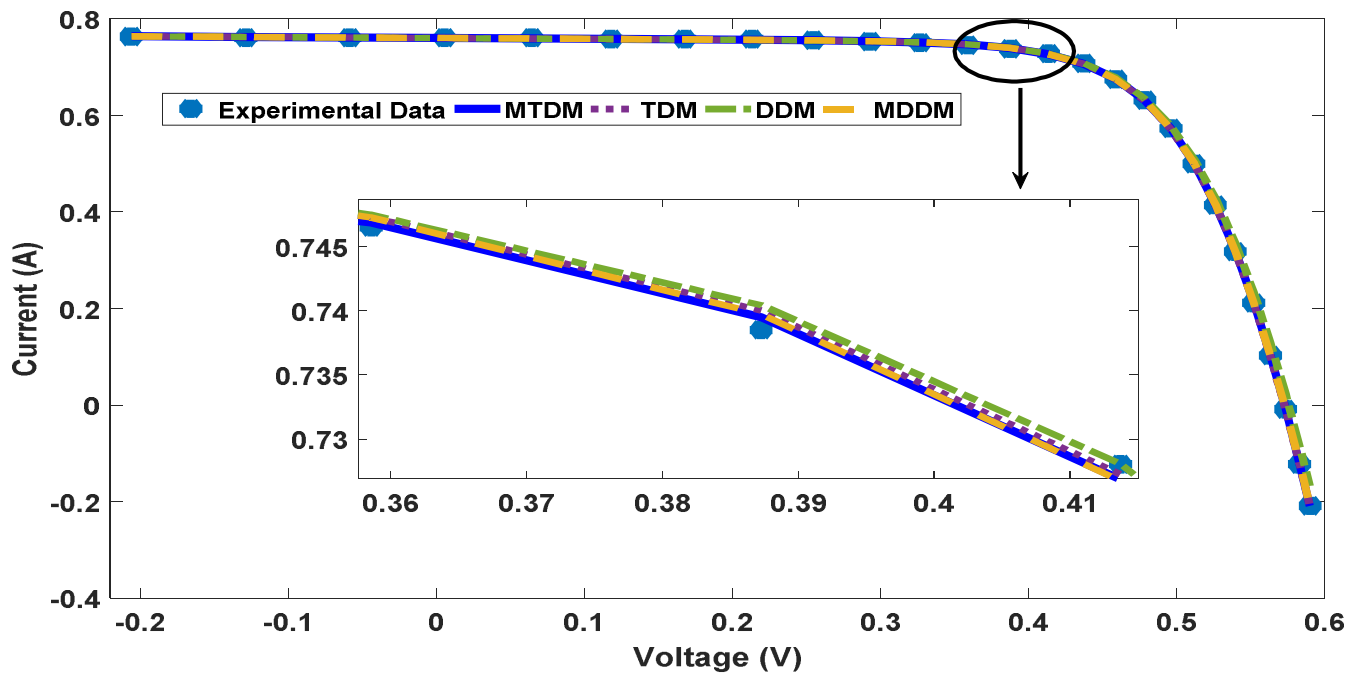

Figure 14. Current-voltage characteristic curve comparison between real data and all estimated models by WHO. 


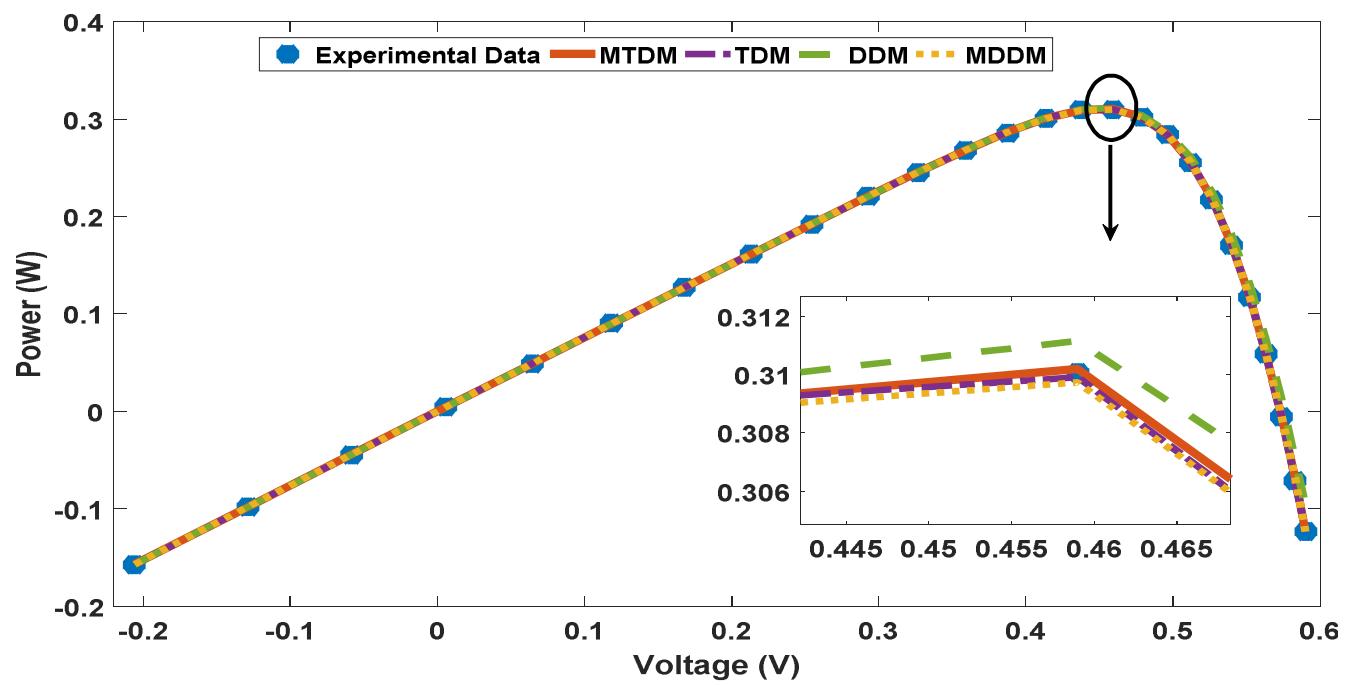

Figure 15. Power-voltage characteristic curve comparison between real data and all estimated models by WHO.

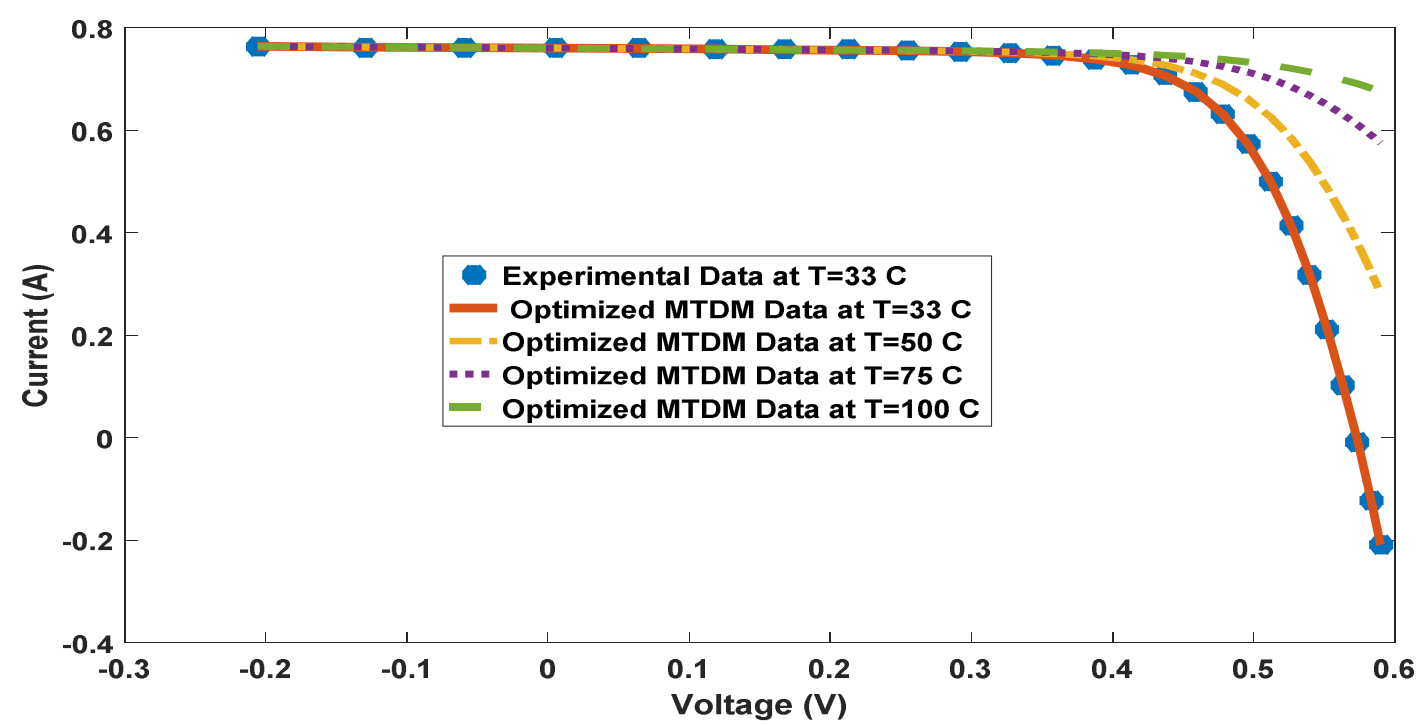

Figure 16. Current-voltage characteristic curve comparison between experimental current and TDM current estimated by WHO at different temperatures.

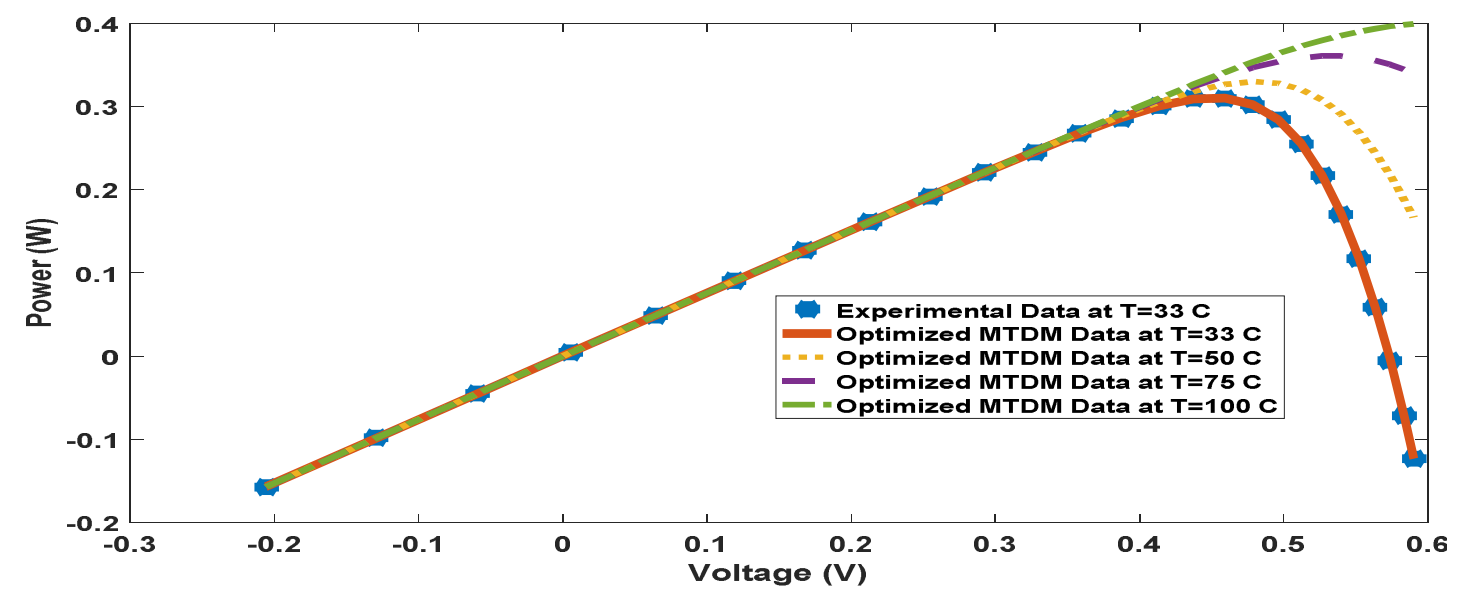

Figure 17. Power-voltage characteristic curve comparison between experimental current and TDM current estimated by WHO at different temperatures. 


\subsection{Results of Potassium Titanate Whisker (PTW) Polycrystalline PV Panels}

This application focused on the comparison of the WHO with other algorithms. A TDM was selected for this comparison, and the real data of the Photowatt-PWP201 PV module was applied $[28,29]$. Photowatt-PWP201 PV module contains 36 polycrystalline silicon cells connected in series and operating at an irradiance of $1000 \mathrm{~W} / \mathrm{m}^{2}$ and temperature of 45C. The accuracy of the WHO's estimated parameters was tested through the best RMSE and compared with recent robust algorithms in literature (I-GWO, CGO, HBO) $[28,29]$. A comparison between the obtained Root Mean Square Errors (RMSE) values for all compared algorithms is presented in Table 5. The convergence curves of the WHO for all compared algorithms are presented in Figure 18. The WHO achieved better speed when compared with I-GWO and HBO, as shown in Figure 18. The WHO's stability was tested by running the algorithm for 30 independent runs and obtaining the statistical analysis of these runs, as presented in Table 6 and graphically simulated through boxplot Figure 19. For more discussion and clarification of results, the current absolute and power absolute errors for all compared algorithms are presented in Figures 20 and 21. Figure 22 presents comparisons between the measured current-voltage characteristic curve and that calculated by different algorithms. Figure 23 presents the power-voltage characteristic curve for the real PV measured data calculated by different algorithms. Figures 22 and 23 show the characteristic curves of the WHO, which were a better fit than other algorithms, to the real characteristic curves, a good indication about the accuracy of the PV model obtained by the WHO.

Table 5. RMSE and estimated parameters for all compared algorithms.

\begin{tabular}{ccccc}
\hline & WHO & I-GWO & CGO & HBO \\
\hline $\mathrm{Rs}_{(}(\Omega)$ & 1.201271011 & 1.198683773 & 1.201271 & 1.199582 \\
\hline $\mathrm{R}_{\mathrm{sh}}(\Omega)$ & 981.9822265 & 986.3365886 & 981.9828 & 983.629 \\
\hline $\mathrm{I}_{\mathrm{ph}}(\mathrm{A})$ & 1.030514299 & 1.030508846 & 1.030514 & 1.030447 \\
\hline $\mathrm{I}_{\mathrm{sd} 1}(\mathrm{~A})$ & $3.48 \times 10^{-6}$ & $1.25 \times 10^{-6}$ & $4.25 \times 10^{-9}$ & $3.48 \times 10^{-7}$ \\
\hline $\mathrm{I}_{\mathrm{sd} 2}(\mathrm{~A})$ & $1.00 \times 10^{-10}$ & $7.77 \times 10^{-7}$ & $4.50 \times 10^{-10}$ & $1.00 \times 10^{-10}$ \\
\hline $\mathrm{I}_{\mathrm{sd} 3}(\mathrm{~A})$ & $1.00 \times 10^{-10}$ & $1.54 \times 10^{-6}$ & $3.48 \times 10^{-6}$ & $3.19 \times 10^{-6}$ \\
\hline$\eta_{1}$ & 48.50792821 & 49.2667226 & 48.50769 & 48.60267 \\
\hline$\eta_{2}$ & 48.50787128 & 48.38422661 & 48.5083 & 49.52947 \\
\hline$\eta_{3}$ & 49.82604479 & 48.25593375 & 48.50793 & 48.56558 \\
\hline $\mathrm{RMSE}$ & 0.002425075 & 0.0024276291 & 0.0024251 & 0.0024281 \\
\hline
\end{tabular}

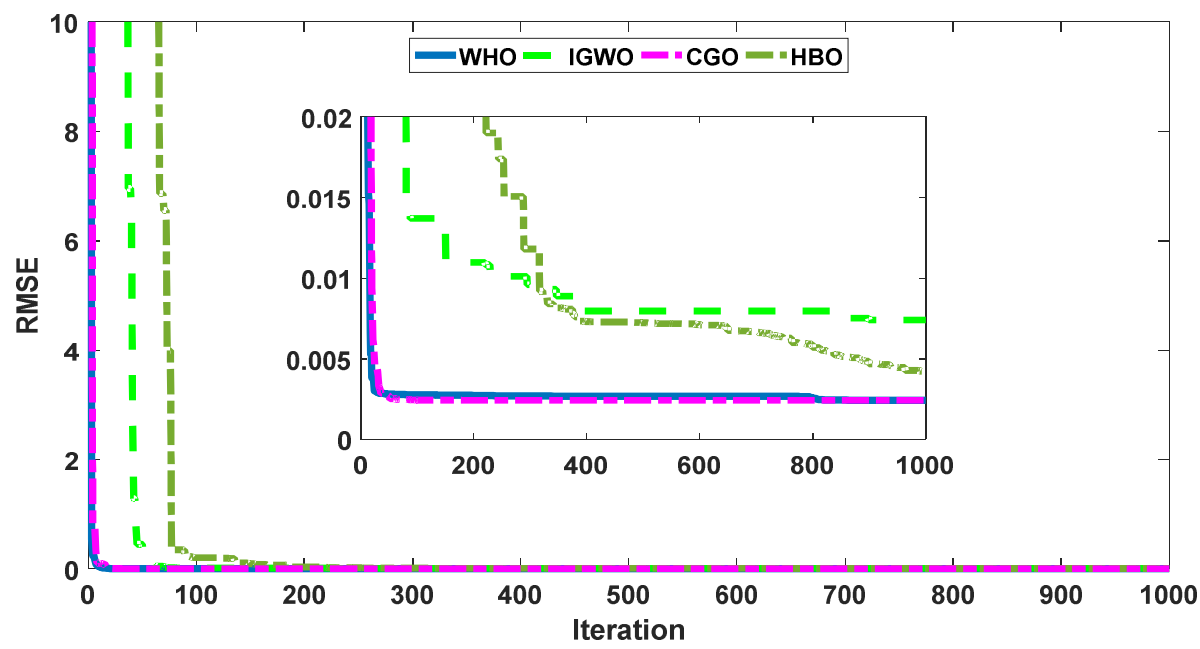

Figure 18. The convergence curve of all algorithms. 
Table 6. The statistical results of WHO and other compared algorithms.

\begin{tabular}{ccccc}
\hline & Minimum & Average & Maximum & STD \\
\hline WHO & 0.002425075 & 0.002425075 & 0.002425075 & $2.16891 \times 10^{-16}$ \\
\hline I-GWO & 0.002427629 & 0.002432 & 0.002438 & $5.26003 \times 10^{-}$ \\
\hline CGO & 0.002425075 & 0.002425092 & 0.0024251 & $1.45 \times 10^{-8}$ \\
\hline HBO & 0.0024281 & 0.002465 & 0.002528 & $5.50757 \times 10^{-5}$ \\
\hline
\end{tabular}

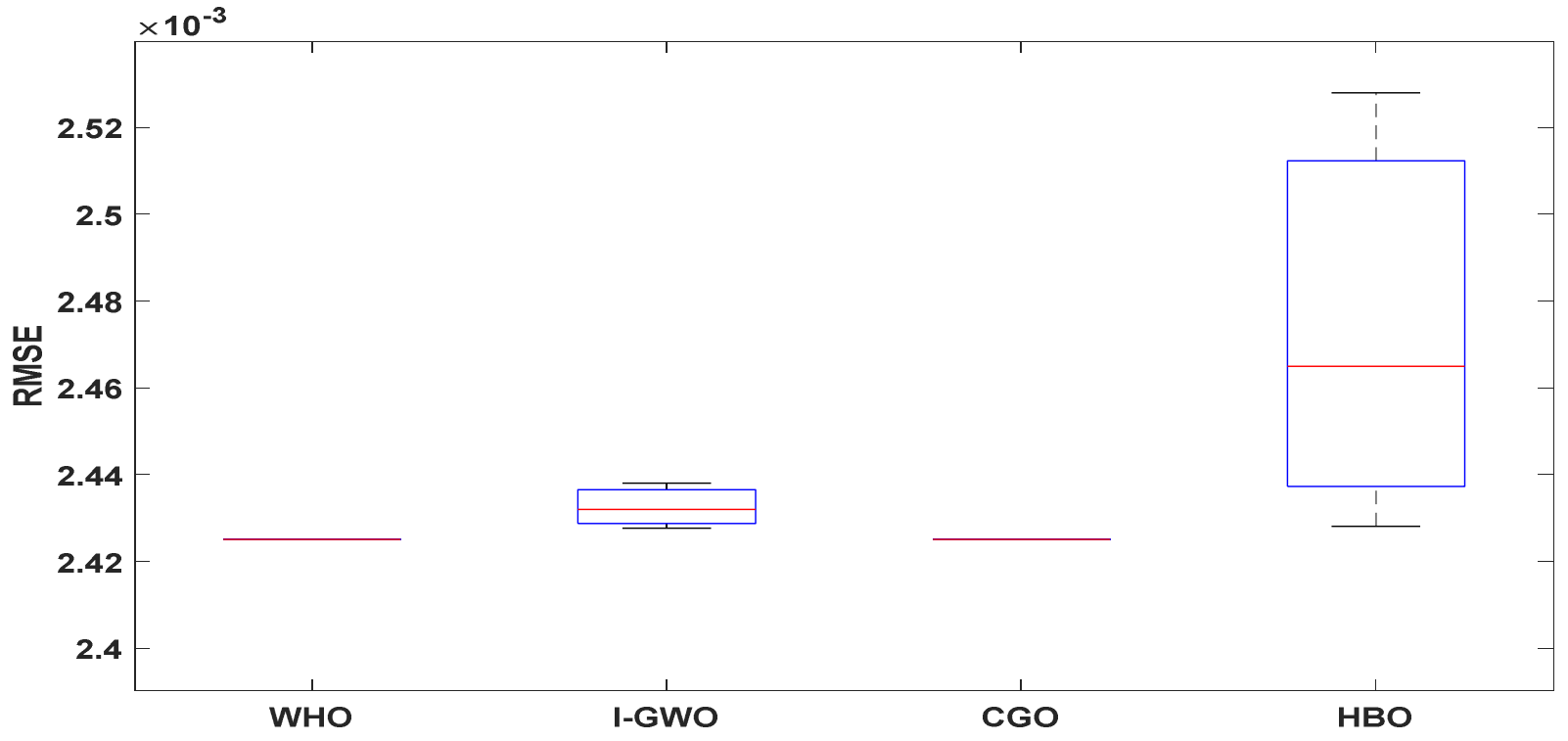

Figure 19. Boxplot for all algorithm for 30 independent runs.

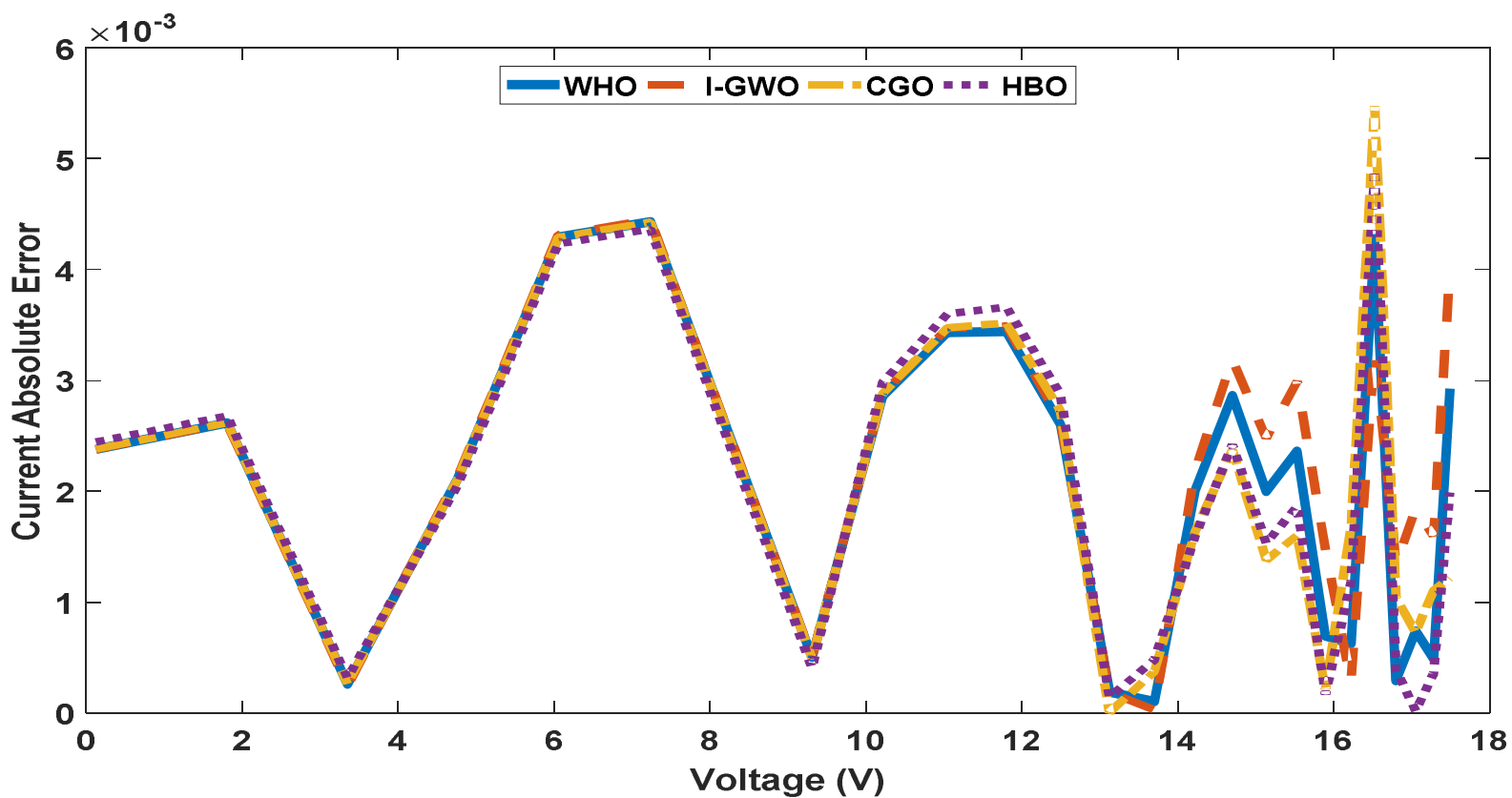

Figure 20. Current absolute error of all algorithms. 


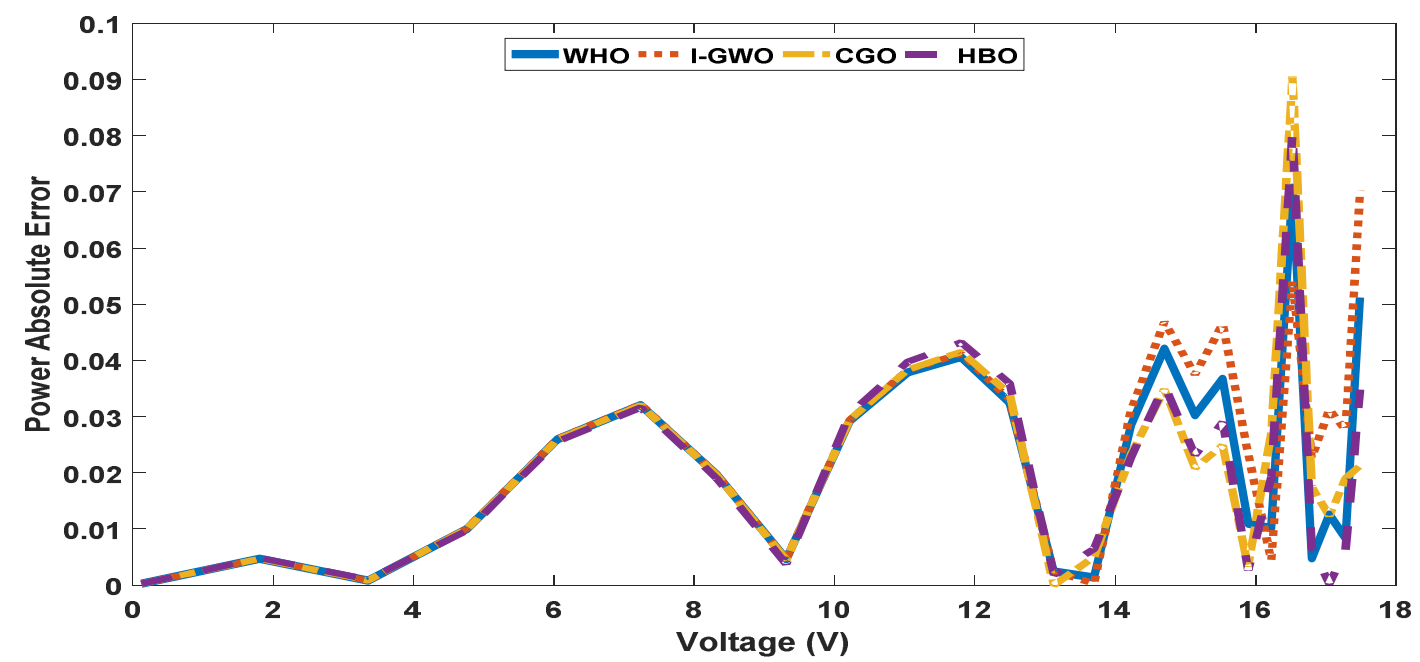

Figure 21. Power absolute error of all algorithms.

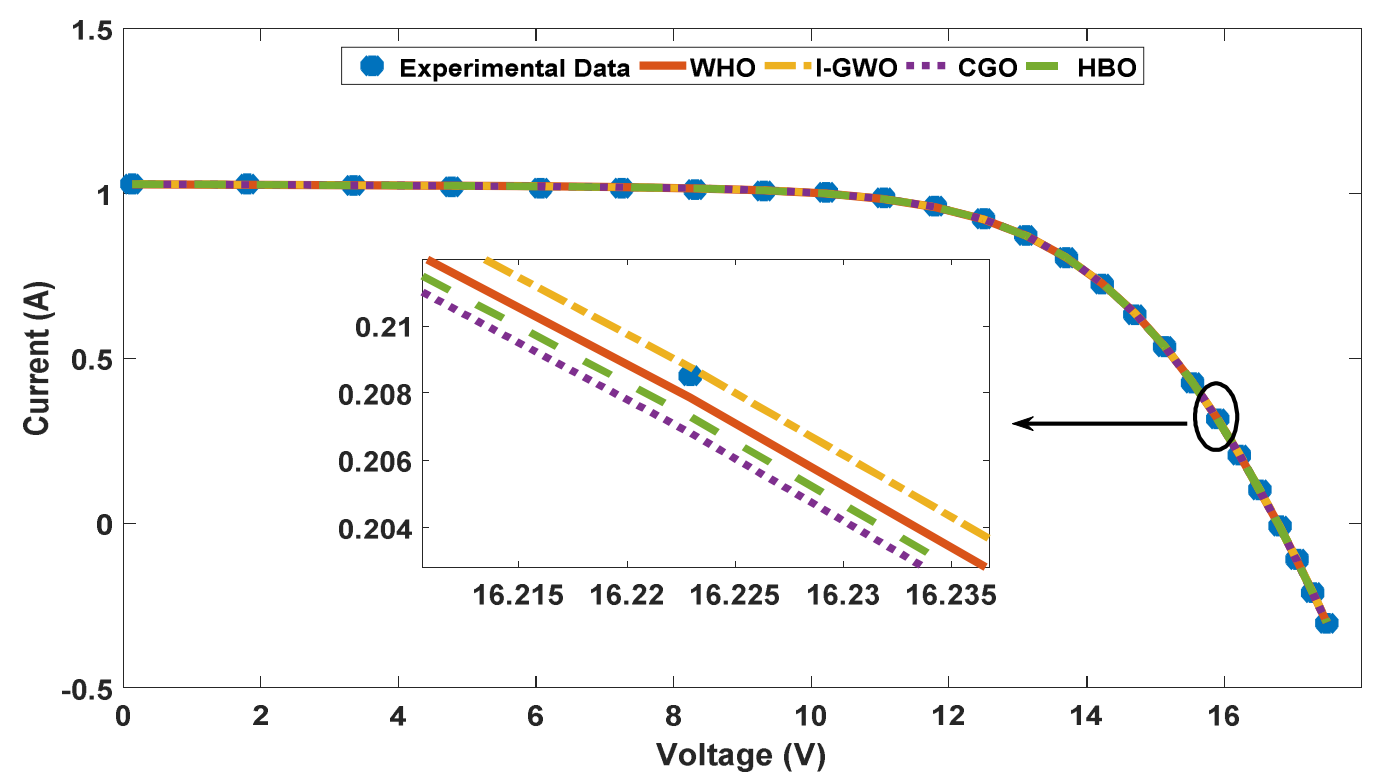

Figure 22. Current-voltage characteristic curve comparison between real data and all estimated TDM by different algorithms.

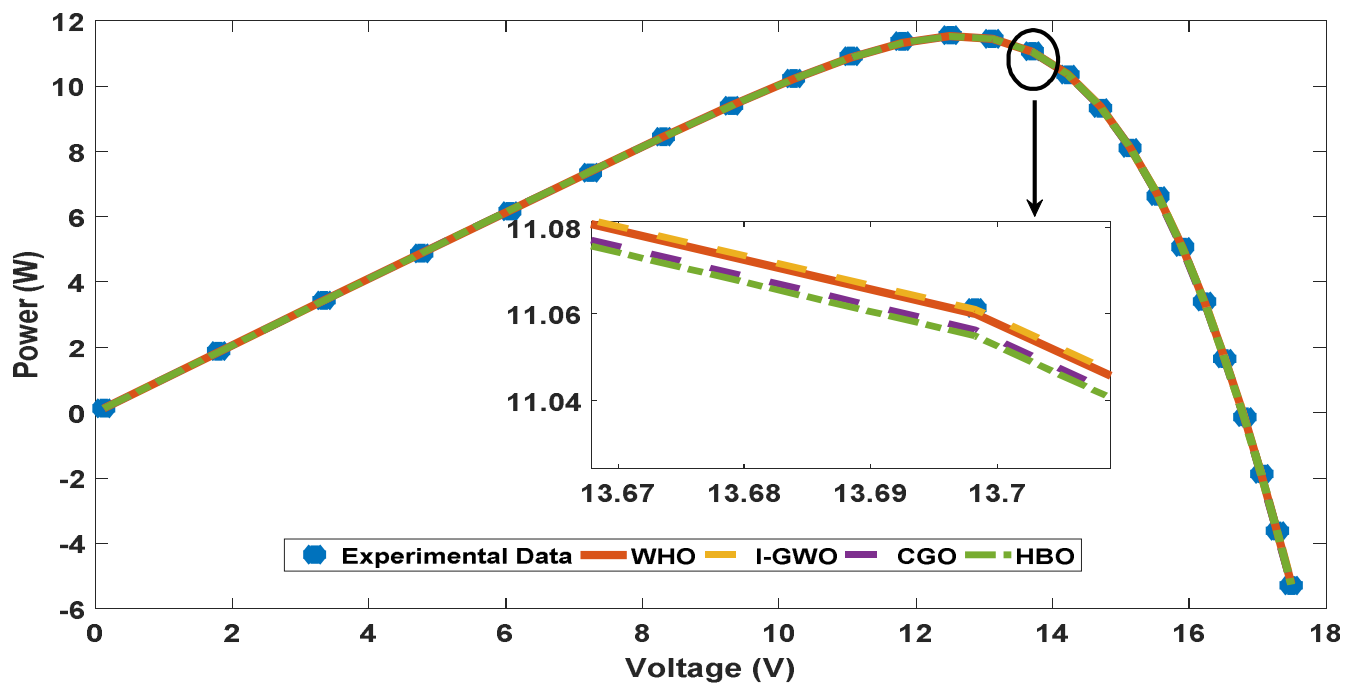

Figure 23. Power-voltage characteristic curve comparison between real data and all estimated TDM by different algorithms. 


\section{Conclusions}

This paper has presented a discussion on the proposed modifications for PV models (MTDM and MDDM) and the differences to its original models, TDM and DDM. The WHO has been used in this study to estimate the parameters for these models. The process of evaluation and testing has been divided into two applications. Application 1 has focused on the comparison between these models. The MTDM and MDDM have the best accuracy when compared with their original models. For more comprehensive analysis, the WHO results have been compared with other recent algorithms proposed in the literature that applied to the same models. The real data of the $57 \mathrm{~mm}$ diameter commercial silicon RTC France solar cell have been used in this application. Application 2 has focused on the performance of the WHO with other recently proposed algorithms. The real data from the polycrystalline Photowatt-PWP201 PV module have been used for this application. The analysis of results in the two applications have been conducted through numerical comparisons such as RMSE values and graphically compared, such as convergence curve to present the algorithm behavior and speed, a boxplot for algorithm robustness through different individual runs, power absolute error and current absolute error have been used for results' accuracy, and finally, the current-voltage characteristics and power-voltage characteristics at different temperatures to test the models' behavior at different operation conditions. The performance of the WHO is satisfied in all applications compared with different evaluation methods. For future work, this study can assist research work that focuses on studying the applicability of the WHO and modified PV models for complex and large PV systems.

Author Contributions: Conceptualization, A.R., S.K. and I.B.M.T.; data curation, A.R., S.K. and I.B.M.T.; formal analysis, A.R., S.K. and M.T.-V.; funding acquisition, S.K. and I.B.M.T.; investigation, A.R., S.K., I.B.M.T. and M.T.-V.; methodology, A.R., I.B.M.T. and M.T.-V.; project administration, A.R., S.K., I.B.M.T. and M.T.-V.; resources, S.K., I.B.M.T. and M.T.-V.; software, A.R., S.K. and I.B.M.T.; supervision, S.K. and I.B.M.T.; validation, I.B.M.T. and M.T.-V.; visualization, M.T.-V.; writing-original draft, A.R. and I.B.M.T.; writing-review and editing, S.K. and M.T.-V. All authors have read and agreed to the published version of the manuscript.

Funding: Taif University Researchers Supporting Project Number (TURSP-2020/61), Taif University, Taif, Saudi Arabia.

Acknowledgments: The authors would like to acknowledge the financial support received from Taif University Researchers Supporting Project Number (TURSP-2020/61), Taif University, Taif, Saudi Arabia.

Conflicts of Interest: The authors declare that there is no conflict of interest.

\section{Nomenclature}

$\begin{array}{ll}\text { Symbol } & \text { Description } \\ \text { TDM } & \text { Triple-Diode Model } \\ \text { DDM } & \text { Double-Diode Model } \\ \text { PV } & \text { Photo Voltaic } \\ \text { I } & \text { PV module output current } \\ \text { V } & \text { Terminal voltage } \\ \mathrm{I}_{\mathrm{ph}} & \text { Current source generated from photons } \\ \eta_{1} & \text { Ideality factor for the first diode (Diffusion current components) } \\ \eta_{3} & \text { Ideality Factor for the third diode (Leakage current components) } \\ \text { Rs } & \text { Series resistance to represent the total semiconductor material at neutral } \\ \text { Is1 } & \text { regions resistance. } \\ \text { Is2 } & \text { Current passing through the First diode } \\ \text { MTDM } & \text { Current passing through the Second diode } \\ \text { MTDM } & \text { Modified Triple-Diode Model } \\ \text { SDM } & \text { Modified Double-Diode Model } \\ \text { R }_{\text {sm }} & \text { Single-Diode Model }\end{array}$




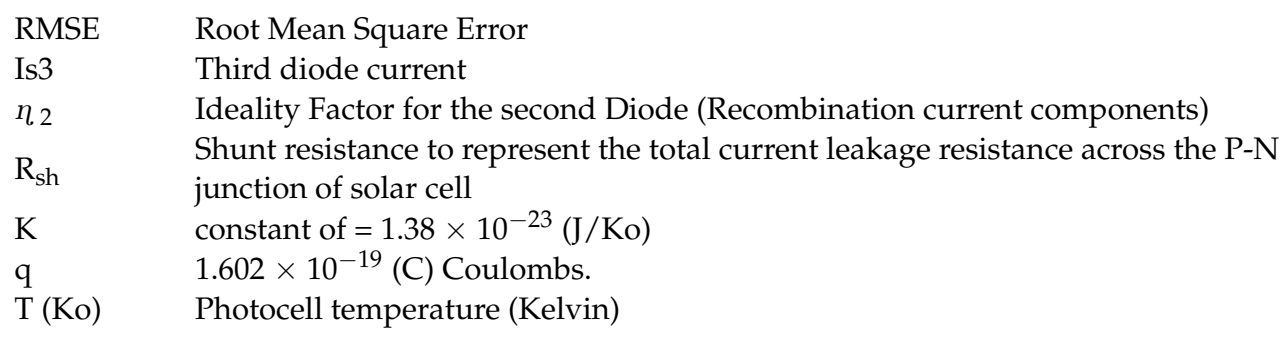

\section{References}

1. Solaymani, S. A Review on Energy and Renewable Energy Policies in Iran. Sustainability 2021, 13, 7328. [CrossRef]

2. Mohammadi, V.; Mozaffari Shamsi, H.; Asadi, F. Investigating the Relationship between Economic Growth, Energy Consumption and Human Development in Selected MENA Countries. J. Energy Econ. 2019, 8, 811-850.

3. Saleem, A.; Rashid, F.; Mehmood, K. The efficiency of solar PV system. In Proceedings of the 2nd International Multidisciplinary Conference, Jakarta, Indonesia, 15-16 November 2016.

4. Yousri, D.; Rezk, H.; Fathy, A. Identifying the parameters of different configurations of photovoltaic models based on recent artificial ecosystem-based optimization approach. Int. J. Energy Res. 2020, 44, 11302-11322. [CrossRef]

5. Tamrakar, V.; Gupta, S.C.; Sawle, Y. Single-Diode PV Cell Modeling and Study of Characteristics of Single and Two-Diode Equivalent Circuit. Electr. Electron. Eng. Int. J. 2015, 4, 12. [CrossRef]

6. Teyabeen, A.A.; Elhatmi, N.B.; Essnid, A.A.; Jwaid, A.E. Parameters estimation of solar PV modules based on single-diode model. In Proceedings of the International Renewable Energy Congress (IREC), Hammamet, Tunisia, 29-31 October 2020.

7. Abdelghany, R.Y.; Kamel, S.; Ramadan, A.; Sultan, H.; Rahmann, C. Solar cell parameter estimation using school-based optimization algorithm. In Proceedings of the International Conference on Automation/XXIV Congress of the Chilean Association of Automatic Control (ICA-ACCA), Santiago, Chile, 22-26 March 2021.

8. Sabadus, A.; Mihailetchi, V.; Paulescu, M. Parameters Extraction for the One-Diode Model of a Solar Cell. In AIP Conference Proceedings; AIP Publishing LLC: Melville, NY, USA, 2017.

9. Shannan, N.M.; Yahaya, N.; Singh, B. Single-diode model and two-diode model of PV modules: A comparison. In Proceedings of the IEEE International Conference on Control System, Computing and Engineering, Penang, Malaysia, 29 November-1 December 2013.

10. Ramadan, A.; Kamel, S.; Korashy, A.; Yu, J. Photovoltaic Cells Parameter Estimation Using an Enhanced Teaching Learning Based Optimization Algorithm. Iran. J. Sci. Technol. 2019, 44, 767-779. [CrossRef]

11. Barth, N.; Jovanovic, R.; Ahzi, S.; Khaleel, M.A. PV Panel Single and Double-Diode Models: Optimization of the Parameters and Temperature Dependence. Sol. Energy Mater. Sol. Cells 2016, 148, 87-98. [CrossRef]

12. Ramadan, A.; Kamel, S.; Ibrahim, A.A. Parameters Estimation of Photovoltaic Cells Using Self-Adaptive Multi-Population Rao Optimization Algorithm. Aswan Univ. J. Sci. Technol. 2021, 31, 34.

13. Messaoud, R.B. Extraction of Uncertain Parameters of Double-Diode Model of a Photovoltaic Panel Using Ant Lion Optimization. Appl. Sci. 2018, 2, 1-8. [CrossRef]

14. Mohammed, H.; Qais, H.; Hasanien, M.; Alghuwainem, S. Parameters Extraction of Three-Diode Photovoltaic Model Using Computation and Harris Hawks Optimization. Energy 2020, 195, 117040.

15. Qais, M.H.; Hasanien, H.M.; Alghuwainem, S. Identification of Electrical Parameters for Three-Diode Photovoltaic Model Using Analytical and Sunflower Optimization Algorithm. Appl. Energy 2019, 250, 109-117. [CrossRef]

16. Elazab, O.S.; Hasanien, H.; Alsaidan, M.; Almoataz, I.; Abdelaziz, Y.; Muyeen, S.M. Parameter Estimation of Triple-Diode Photovoltaic Model Using Grasshopper Optimization Algorithm. Energies 2020, 13, 497. [CrossRef]

17. Chin, V.J.; Salam, Z. A New Three-point-based Approach for the Parameter Extraction of Photovoltaic Cells. Appl. Energy 2019, 237, 519-533. [CrossRef]

18. Ramadan, A.; Kamel, S.; Hassan, M.H.; Khurshaid, T.; Rahmann, C. An Improved Bald Eagle Search Algorithm for Parameter Estimation of Different Photovoltaic Models. Processes 2021, 9, 1127. [CrossRef]

19. Bayoumi, A.S.; El-Sehiemy, R.A.; Mahmoud, K.; Lehtonen, M.; Darwish, M.M.F. Assessment of an Improved Three-Diode against Modified Two-Diode Patterns of MCS Solar Cells Associated with Soft Parameter Estimation Paradigms. Appl. Sci. 2021, 11, 1055. [CrossRef]

20. Abdelminaam, D.S.; Said, M.; Houssein, E.H. Turbulent Flow of Water-Based Optimization Using New Objective Function for Parameter Extraction of Six Photovoltaic Models. IEEE Access 2021, 9, 35382-35398. [CrossRef]

21. Reis, L.R.D.; Camacho, J.R.; Novacki, D.F. The Newton-Raphson method in the extraction of parameters of PV modules. In Proceedings of the International Conference on Renewable Energies and Power Quality (ICREPQ 2017), Malaga, Spain, 4-6 April 2017.

22. Nayak, B.K.; Mohapatra, A.; Mohanty, K.B. Parameters estimation of photovoltaic module using nonlinear least square algorithm: A comparative study. In Proceedings of the Annual IEEE India Conference (INDICON 2013), Mumbai, India, 13-15 December 2013.

23. Sharma, A.; Sharma, A.; Averbukh, M.; Jately, V.; Azzopardi, B. An Effective Method for Parameter Estimation of a Solar Cell. Electronics 2021, 10, 312. [CrossRef] 
24. Giagkiozis, I.; Purshouse, R.C.; Fleming, P.J. An Overview of Population-Based Algorithms for Multi-Objective Optimization. Int. J. Syst. Sci. 2013, 46, 1572-1599. [CrossRef]

25. Saha, V.O.C.; al Bazi, A.; Guha, K. Optimisation of Solar Photovoltaic (PV) Parameters Using Metaheuristics. Microsyst. Technol. 2021, 27, 3161-3169.

26. Said, M.; Abdullah, M.; Shaheen, A.; Ginidi, R.; El-Sehiemy, R.A.; Mahmoud, K.; Lehtonen, M.; Darwish, M.M.F. Estimating Parameters of Photovoltaic Models Using Accurate Turbulent Flow of Water Optimizer. Processes 2021, 9, 627. [CrossRef]

27. Abdel-Basset, M.; Mohamed, R.; Mirjalili, S.; Chakrabortty, R.K.; Ryan, M.J. Solar Photovoltaic Parameter Estimation Using an Improved Equilibrium Optimizer. Sol. Energy 2020, 209, 694-708. [CrossRef]

28. Ramadan, A.; Kamel, S.; Hussein, M.M.; Hassan, M.H. A New Application of Chaos Game Optimization Algorithm for Parameters Extraction of Triple-Diode Photovoltaic Model. IEEE Access 2021, 9, 51582-51594. [CrossRef]

29. Ramadan, A.; Kamel, S.; Khurshaid, T.; Oh, S.; Rhee, S. Parameter Extraction of Triple-Diode Solar Photovoltaic Model Using Improved Grey Wolf Optimizer. Sustainability 2021, 13, 6963. [CrossRef]

30. Naruei, I.; Keynia, F. Wild Horse Optimizer: A New Meta Heuristic Algorithm for Solving Engineering Optimization Problems. Eng. Comput. 2021. [CrossRef] 